\title{
Constraints on methane emissions in North America from future geostationary remote-sensing measurements
}

\author{
Nicolas Bousserez ${ }^{1}$, Daven K. Henze ${ }^{1}$, Brigitte Rooney ${ }^{1}$, Andre Perkins ${ }^{1, \text { a }}$, Kevin J. Wecht ${ }^{3}$, Alexander J. Turner ${ }^{3}$, \\ Vijay Natraj ${ }^{2}$, and John R. Worden ${ }^{2}$ \\ ${ }^{1}$ Department of Mechanical Engineering, University of Colorado, Boulder, CO, USA \\ ${ }^{2}$ Jet Propulsion Laboratory, California Institute of Technology, Pasadena, CA, USA \\ ${ }^{3}$ School of Engineering and Applied Sciences, Harvard University, Cambridge, MA, USA \\ ${ }^{a}$ now at: Department of Atmospheric Sciences, University of Washington, Seattle, WA, USA
}

Correspondence to: Nicolas Bousserez (nicolas.bousserez@ colorado.edu)

Received: 21 April 2015 - Published in Atmos. Chem. Phys. Discuss.: 10 July 2015

Revised: 25 March 2016 - Accepted: 15 April 2016 - Published: 20 May 2016

\begin{abstract}
The success of future geostationary (GEO) satellite observation missions depends on our ability to design instruments that address their key scientific objectives. In this study, an Observation System Simulation Experiment (OSSE) is performed to quantify the constraints on methane $\left(\mathrm{CH}_{4}\right)$ emissions in North America obtained from shortwave infrared (SWIR), thermal infrared (TIR), and multi-spectral (SWIR+TIR) measurements in geostationary orbit and from future SWIR low-Earth orbit (LEO) measurements. An efficient stochastic algorithm is used to compute the information content of the inverted emissions at high spatial resolution $\left(0.5^{\circ} \times 0.7^{\circ}\right)$ in a variational framework using the GEOSChem chemistry-transport model and its adjoint. Our results show that at sub-weekly timescales, SWIR measurements in GEO orbit can constrain about twice as many independent flux patterns than in LEO orbit, with a degree of freedom for signal (DOF) for the inversion of 266 and 115, respectively. Comparisons between TIR GEO and SWIR LEO configurations reveal that poor boundary layer sensitivities for the TIR measurements cannot be compensated for by the high spatiotemporal sampling of a GEO orbit. The benefit of a multi-spectral instrument compared to current SWIR products in a GEO context is shown for sub-weekly timescale constraints, with an increase in the DOF of about $50 \%$ for a 3-day inversion. Our results further suggest that both the SWIR and multi-spectral measurements on GEO orbits could almost fully resolve $\mathrm{CH}_{4}$ fluxes at a spatial resolution of at least $100 \mathrm{~km} \times 100 \mathrm{~km}$ over source hotspots (emissions $\left.>4 \times 10^{5} \mathrm{~kg} \mathrm{day}^{-1}\right)$. The sensitivity of the optimized emis-
\end{abstract}

sion scaling factors to typical errors in boundary and initial conditions can reach 30 and $50 \%$ for the SWIR GEO or SWIR LEO configurations, respectively, while it is smaller than $5 \%$ in the case of a multi-spectral GEO system. Overall, our results demonstrate that multi-spectral measurements from a geostationary satellite platform would address the need for higher spatiotemporal constraints on $\mathrm{CH}_{4}$ emissions while greatly mitigating the impact of inherent uncertainties in source inversion methods on the inferred fluxes.

\section{Introduction}

Methane $\left(\mathrm{CH}_{4}\right)$ plays a key role in both atmospheric chemistry composition and climate. With a radiative forcing relative to preindustrial times that is one-third that of carbon dioxide, $\mathrm{CH}_{4}$ is the second most important greenhouse gas (Myhre and Shindell, 2013). Furthermore, as a precursor to tropospheric ozone, $\mathrm{CH}_{4}$ also impacts surface-level air quality (Fiore et al., 2002; West et al., 2006; West and Fiore, 2005) and crops (e.g., Shindell et al., 2012), and contributes to ozone radiative forcing (e.g., Fiore et al., 2008). Considerable uncertainty remains in our understanding of $\mathrm{CH}_{4}$ sources (e.g., Dlugokencky et al., 2011; Kirschke et al., 2013), which include emissions from coal, wetlands, livestock, landfills, biomass burning, geologic seepage, and leaks from the production and distribution of natural gas.

Although there is a growing interest in using $\mathrm{CH}_{4}$ emission regulations as an efficient lever to simultaneously ad- 
dress current air quality and global warming challenges (e.g., West et al., 2012), the lack of confidence in the available $\mathrm{CH}_{4}$ emission estimates remains a problematic limitation to the design of efficient environmental policies. Indeed, recent studies showed discrepancies of up to a factor of 2 between bottom-up inventories and top-down inversions using atmospheric $\mathrm{CH}_{4}$ concentration observations (Katzenstein et al., 2003; Kort et al., 2008; Xiao et al., 2008; Karion et al., 2013; Miller et al., 2013; Wecht et al., 2012, 2014a; Caulton et al., 2014; Turner et al., 2015). Extrapolation of local emission characteristics to larger areas and/or the use of proxy data (e.g., energy consumption, emission ratios applied to co-emitted species) are the main sources of error in bottomup methods. On the other hand, top-down approaches using space-based measurements of $\mathrm{CH}_{4}$ from low-Earth orbit (LEO) platforms allow a global spatial coverage within 1 to 6 days but at the same local time. However, as $\mathrm{CH}_{4}$ emissions can exhibit significant diurnal cycles, e.g., over wetland or boreal peatland (Morin et al., 2014; Gazovic et al., 2010), such temporal undersampling may affect our ability to accurately quantify those fluxes. More generally, insufficient observational coverage and the diffusive nature of transport considerably reduce our ability to spatially resolve grid-scale emissions from space.

Geostationary (GEO) remote-sensing measurements would alleviate the above-mentioned shortcomings by providing an almost continuous monitoring and complete spatial coverage of $\mathrm{CH}_{4}$ concentrations within the field of view. Previous studies have already demonstrated the potential of column-integrated trace gas measurements from geostationary satellites to constrain surface fluxes at regional scale, from single mega-city emissions down to power plant sources (Polonsky et al., 2014; Rayner et al., 2014). The GEOstationary Coastal and Air Pollution Events (GEOCAPE) mission (Fishman et al., 2012) was recommended by the National Research Council's Earth Science Decadal Survey in order to improve our understanding of both coastal ecosystems and air quality from regional to continental scale. Its aim is to enable multiple daily observations of key atmospheric and oceanic constituents over North and South America from a GEO platform. For air-quality applications, such high-spatial and high-temporal-resolution measurements would enable source estimates of air-quality pollutants and climate forcers and development of effective emission-control strategies at an unprecedented level of confidence. In order to provide more flexibility and to minimize the cost and risk of the mission, the concept of a phased implementation that would launch remote-sensing instruments separately on commercial host spacecrafts has been adopted. The first phase will consist of the launching of the Tropospheric Emissions: Monitoring of Pollution (TEMPO) instrument circa 2019 (Chance et al., 2013), which will provide GEO hourly measurements of ozone and precursors as well as aerosols over greater North America (from Mexico City to the Canadian tar sands, and from the
Atlantic to Pacific oceans). For the second phase, which aims at completing GEO-CAPE's mission requirements by including measurements of important drivers of climate and air quality such as $\mathrm{CH}_{4}, \mathrm{CO}$, and ammonia (Zhu et al., 2015), a rigorous instrument design study is critical to achieve the mission's scientific objectives within its budget constraints.

In this study we perform an Observation System Simulation Experiment (OSSE) in order to characterize the constraints on grid-scale $\mathrm{CH}_{4}$ emissions over North America provided by different potential GEO-CAPE instrument configurations. The simulation consists of a 4D-Var inversion of $\mathrm{CH}_{4}$ emissions using the GEOS-Chem chemical-transport model $(\mathrm{CTM})$ over a $0.5^{\circ} \times 0.7^{\circ}$ horizontal grid resolution covering North America. In practice, quantifying the information content of such a high-dimensional problem requires either Monte Carlo simulations or, for linear models, a numerical approximation of the inverse Hessian matrix of the 4D-Var cost function (Tarantola, 2005). Although previous studies have used Monte Carlo estimates (e.g., Chevallier et al., 2007; Liu et al., 2014; Cressot et al., 2014), their computational cost can be extremely high. Indeed, many perturbed inversions (typically about 50) are needed, each of them requiring numerous forward and adjoint model integrations (iterations) in case the problem is not well conditioned (about 50 iterations for our methane inversion). Alternatively, inverse Hessian approximations based on information from the minimization itself can be employed, but are usually of very low rank (e.g., Meirink et al., 2008; Bousserez et al., 2015). Therefore, most information content analyses in previous trace-gas Bayesian inversion studies have relied on explicit calculations of the inverse Hessian matrix, by either considering a regional domain (e.g., Wecht et al., 2014a) or performing a prior dimension reduction of the control vector (e.g., Wecht et al., 2014b; Turner and Jacob, 2015). However, thus far dimension reduction methods for high-dimensional problems have relied on suboptimal choices for the reduced space, which preclude an accurate and objective quantification of the spatiotemporal constraints on the optimized emissions.

In this study we use a gradient-based randomization algorithm to approximate the inverse Hessian of the cost function (Bousserez et al., 2015), which allows us to calculate the posterior errors as well as the model resolution matrix (or averaging kernel) of our $\mathrm{CH}_{4}$ emission inversion at grid-scale resolution. Such information is used to evaluate the impact of different instrumental designs (spatiotemporal sampling, vertical sensitivity of the measurements) on $\mathrm{CH}_{4}$ emission constraints. In particular, the potential of $\mathrm{CH}_{4}$ retrievals from the future TROPOspheric Monitoring Instrument (TROPOMI) shortwave infrared (SWIR) measurements in a LEO orbit as well as from a hypothetical multi-spectral instrument in a geostationary orbit are examined. Section 2 describes the OSSE framework considered in this study, which comprises the 4D-Var method, the forward model, as well as the observations and prior information used. Section 3 presents the 
results of our experiments, where the information content of the inversion is analyzed in detail. A conclusion to this work is presented in the last section of the paper.

\section{Inverse method}

\subsection{D-Var system and information content}

The variational approach to Bayesian inference is the method of choice for high-dimensional problems, since the solution can be computed by iteratively minimizing a cost function instead of algebraically solving for the minimum, which becomes computationally intractable for high-dimensional systems. Provided the error statistics are all Gaussian, finding the maximum likelihood entails solving the following problem:

$$
\begin{array}{rl}
\arg \min _{\boldsymbol{x}} & J(\boldsymbol{x}) \\
J(\boldsymbol{x}) & =\frac{1}{2}(H(\boldsymbol{x})-\boldsymbol{y})^{T} \mathbf{R}^{-1}(H(\boldsymbol{x})-\boldsymbol{y}) \\
& +\frac{1}{2}\left(\boldsymbol{x}-\boldsymbol{x}_{\mathrm{b}}\right)^{T} \mathbf{B}^{-1}\left(\boldsymbol{x}-\boldsymbol{x}_{\mathrm{b}}\right),
\end{array}
$$

where $x_{\mathrm{b}}$ is the prior vector, defined in the control space $E$ of dimension $n, \boldsymbol{x}$ belongs to $E, \boldsymbol{y}$ is the observation vector, defined in the observations vector space $F$ of dimension $p$, $H: E \rightarrow F$ is the forward model operator (also called the observational operator), which associates with any vector in $E$ its corresponding observation in $F$, and $\mathbf{R}$ and $\mathbf{B}$ are the covariance matrices of the observation and prior errors with dimension $(p \times p)$ and $(n \times n)$, respectively. The argument of the minimum of Eq. (1) is called the analysis and is referred to as $\boldsymbol{x}_{\mathrm{a}}$.

When the adjoint of the forward model $\left(\mathbf{H}^{T}\right)$ is available, the minimum of the cost function $J$ can be found iteratively using a gradient-based minimization algorithm (Lions, 1971). The gradient of the cost function with respect to the control vector $\boldsymbol{x}$ can be written as

$\nabla J(\boldsymbol{x})=\mathbf{H}^{T} \mathbf{R}^{-1}(H(\boldsymbol{x})-\boldsymbol{y})+\mathbf{B}^{-1}\left(\boldsymbol{x}-\boldsymbol{x}_{\mathrm{b}}\right)$.

An important result is that if the forward model is approximately linear, the posterior error covariance matrix $\mathbf{P}^{\mathrm{a}}$ is equal to the inverse of the Hessian of the cost function:

$\mathbf{P}^{\mathrm{a}}=\left(\nabla^{2} J\right)^{-1}\left(\boldsymbol{x}_{\mathrm{a}}\right)=\left(\mathbf{B}^{-1}+\mathbf{H}^{T} \mathbf{R}^{-1} \mathbf{H}\right)^{-1}$.

This equivalence can be used to compute information content diagnostics prior to performing the inversion. In this study, following Bousserez et al. (2015), the diagonal elements of $\mathbf{P}^{\mathbf{a}}$ (error variances) are computed using a randomization estimate of $\mathbf{H}^{T} \mathbf{R}^{-1} \mathbf{H}$. Here an ensemble of 500 random gradients of the cost function are used, based on the convergence of the uniform norm $\left(\|\cdot\|_{\infty}\right)$ of the inverse Hessian approximation. Bousserez et al. (2015) showed that good approximation of both the error variances and the error correlations can be obtained using this approach. For the present study we further validated our method by comparing direct finite-difference estimates of selected diagonal elements of $\mathbf{P}^{\mathrm{a}}$ to their stochastic approximations, and found a relative error standard deviation smaller than $10 \%$.

The model resolution matrix (or averaging kernel $\mathbf{A}$ ) is defined as the sensitivity of the analysis $\boldsymbol{x}_{\mathrm{a}}$ (optimized $\mathrm{CH}_{4}$ emissions) to the truth $\boldsymbol{x}_{\mathrm{t}}$ (true emissions):

$\mathbf{A} \equiv \frac{\partial \boldsymbol{x}_{\mathrm{a}}}{\partial \boldsymbol{x}_{\mathrm{t}}}$.

The model resolution matrix in Eq. (4) can be rewritten in matrix form:

$\mathbf{A}=\mathbf{I}-\mathbf{P}^{\mathrm{a}} \mathbf{B}^{-1}$.

Since $\mathbf{B}$ is diagonal in our experiments, Eq. (5) allows us to calculate any element of $\mathbf{A}$ using

$\mathbf{A}_{i, j}=\delta_{i j}-\frac{\mathbf{P}_{i, j}^{\mathrm{a}}}{\mathbf{B}_{j, j}}$.

Finally, the degree of freedom for signal (DOF) of the inversion is defined as the trace of $\mathbf{A}$, that is, DOF $=\sum_{i} \mathbf{A}_{i, i}$.

\subsection{Forward model and prior emissions}

The forward model in Eq. (1) includes the GEOS-Chem chemistry-transport model, which relates the $\mathrm{CH}_{4}$ emissions to the 3-D concentration field of atmospheric $\mathrm{CH}_{4}$, and the satellite observation operator that transforms the $\mathrm{CH}_{4}$ concentration profiles into their corresponding retrieved profile or columns. The GEOS-Chem simulation used in our experiment is described in Wecht et al. (2014a) and Turner et al. (2015). It consists of a nested simulation over North America at $0.5^{\circ} \times 0.7^{\circ}$ horizontal resolution and 72 vertical levels, driven by offline meteorological data provided by GEOS-5 reanalysis from the NASA Global Modeling and Assimilation Office (GMAO). Boundary conditions for the nested domain are used every $3 \mathrm{~h}$ from a global $4^{\circ} \times 5^{\circ}$ GEOS-Chem simulation. In the case of profile assimilation (multi-spectral instrument), the application of the measurement averaging kernels to the model profiles can be written as follows:

$\ln \mathbf{z}_{\mathrm{retr}}=\ln \mathbf{z}_{\mathrm{a}}+\mathbf{A}\left(\ln \mathbf{z}_{\mathrm{mod}}-\ln \mathbf{z}_{\mathrm{a}}\right)$,

where $\mathbf{z}_{\text {retr }}$ is the profile that would be retrieved if the modeled profile concentrations $\left(\mathbf{z}_{\mathrm{mod}}\right)$ were sounded, and $\mathbf{z}_{\mathrm{a}}$ represents the prior profile concentrations. In the case of $X_{\mathrm{CH}_{4}}$ columns assimilation, we obtain (Parker et al., 2011)

$X_{\mathrm{CH}_{4}}=\frac{X_{\mathrm{CO}_{2}}}{\Omega_{\mathrm{CO}_{2}}}\left(\Omega_{\mathrm{a}}+\mathbf{a}^{T}\left(\omega_{\bmod }-\omega_{\mathrm{a}}\right)\right)$,

where $\omega_{\text {mod }}$ is the modeled vertical profile of methane, $\omega_{a}$ is the a priori profile, $\Omega_{\mathrm{a}}$ is the corresponding a priori column concentration of methane, $\mathbf{a}$ is a column averaging kernel vector that describes the sensitivity as a function of altitude, 
$\Omega_{\mathrm{CO}_{2}}$ is the measured vertical column concentration of $\mathrm{CO}_{2}$, and $X_{\mathrm{CO}_{2}}$ is a modeled column mixing ratio of $\mathrm{CO}_{2}$. For simplicity, we use a single averaging kernel for each instrument. A larger ensemble of averaging kernels describing a potential range of sensitivities is beyond the scope of this study given the computational cost. However, based on knowledge of thermal IR (e.g., TES) and total column (e.g., TROPOMI) retrievals, use of a single averaging kernel is a reasonable approximation as our study is constrained to Northern Hemisphere summertime where the temperature and sunlight conditions provide a sufficient signal for the present evaluation, and because our study looks at the relative merits of different observing approaches.

The prior methane emissions we use are from the EDGARv4.2 anthropogenic methane inventory (European Commission, 2011), the wetland model from Kaplan (2002) as implemented by Pickett-Heaps et al. (2011), the GFED3 biomass burning inventory (van der Werf et al., 2010), a termite inventory and soil absorption from Fung et al. (1991), and a biofuel inventory from Yevich and Logan (2003). Figure 1 shows the total average daily prior methane emissions for the entire North America nested domain. Strong hotspots of $\mathrm{CH}_{4}$ sources clearly appear over the Canadian wetlands, the Appalachian Mountains (an extensive coal mining area) and densely urbanized areas (e.g., southern California and the eastern coast). Following previous assessments of the range of the prior error (Wecht et al., 2014a; Turner et al., 2015), we assume a relative prior standard error of $40 \%$ for our bottom-up emission inventory in every grid cell. This results in a $2.9 \mathrm{Tg}$ month $^{-1}$ uncertainty in the total emission budget over North America, a magnitude comparable to the correction to the prior budget found in the inversion of Turner et al. (2015) of $2.3 \mathrm{Tg}$ month $^{-1}$. We assume no prior spatial error correlations, which means that the matrix $\mathbf{B}$ in Eq. (1) is diagonal. Accurately defining error correlations in bottomup inventories is a challenging problem due to the sparsity of available flux measurements, and is beyond the scope of our study. However, it is likely that the diagonal $\mathbf{B}$ assumption made in our study is overly optimistic, which may result in an overestimation of the spatial resolution of the constraints afforded by the satellite measurements. Note that in our setup one emission scaling factor is optimized per grid cell; therefore, the temporal variability of the emissions is assumed to be a hard constraint at scales smaller than the assimilation window.

\subsection{Observations and model uncertainties}

We consider several instrument configurations for our study, which are associated with different vertical sensitivities: the future TROPOMI instrument (2016 launch), which will measure in the shortwave infrared (SWIR); the Tropospheric Emission Spectrometer (TES) V005 Lite product (Worden et al., 2012) (http://tes.jpl.nasa.gov/data/), which consists of $\mathrm{CH}_{4}$ vertical profile retrievals from thermal infrared (TIR)

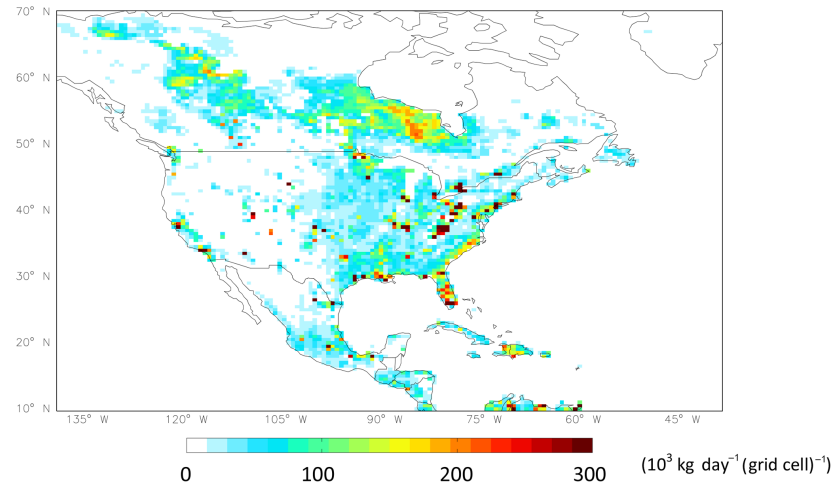

Figure 1. Total daily average prior methane emissions for the nested North America domain $\left(0.5^{\circ} \times 0.7^{\circ}\right)$.

measurements at $7.58-8.55 \mu \mathrm{m}$; and a hypothetical multispectral $\mathrm{CH}_{4}$ profile retrieval, which allows us to capture a signal in the boundary layer. Since the DOF for the TES retrievals is less than 2, we use a pressure-weighted TES $X_{\mathrm{CH}_{4}}$ column instead of the retrieved $\mathrm{CH}_{4}$ profiles. The averaging kernel for the TROPOMI configuration is taken from the Greenhouse gases Observing SATellite (GOSAT) Proxy XCH4 v3.2 retrieval described by Parker et al. (2011) (available from http://www.leos.le.ac.uk/GHG/data/), which consists of $\mathrm{CH}_{4}$ column mixing ratios $\left(\mathrm{X}_{\mathrm{CH}_{4}}\right)$ obtained from SWIR measurements near $1.6 \mu \mathrm{m}$. As noted in Wecht et al. (2014b), the difference between the TROPOMI and GOSAT retrievals are of little consequence, as the averaging kernel for SWIR observations is near unity in the troposphere in any case. The multi-spectral averaging kernel is derived by first combining the Jacobians (or sensitivities) of the modeled radiances to methane concentrations from the 1.6 and $8 \mu \mathrm{m}$ bands. Both the TES and GOSAT retrievals also simultaneously estimate interferences such as clouds, albedo, emissivity, temperature, and $\mathrm{H}_{2} \mathrm{O}$. The effects of these interferences can be included by further combining their corresponding Jacobians with the methane Jacobians (e.g., Worden et al., 2004; Kulawik et al., 2006; Butz et al., 2010). Constraints for methane and the other radiative interferences are described in Worden et al. (2012) and Parker et al. (2011). The combination of these Jacobians and constraints are then used to calculate the averaging kernel. The methane component of the resulting multi-spectral, multi-species averaging kernel is then used for this study. The effect of the interferences with this simultaneous retrieval approach is to reduce the overall sensitivity to methane but improve the posteriori errors. A proof of concept for combining near-IR and IRbased methane estimates to derive a lower tropospheric estimate is discussed in Worden et al. (2015) using GOSAT and TES profile retrievals.

Figure 2 shows the column averaging kernel for the TROPOMI and TES $X_{\mathrm{CH}_{4}}$ retrievals as well as the averaging kernels at three different levels for the multi-spectral 

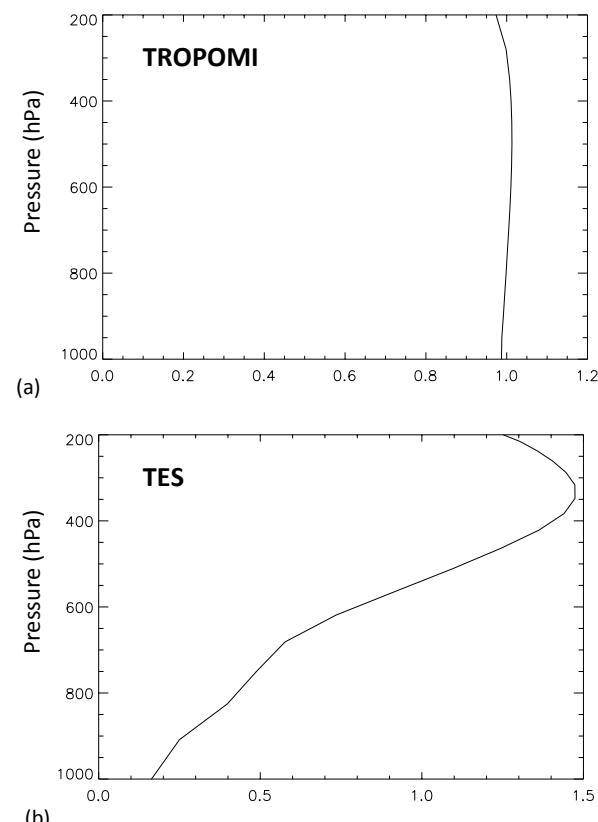

(b)

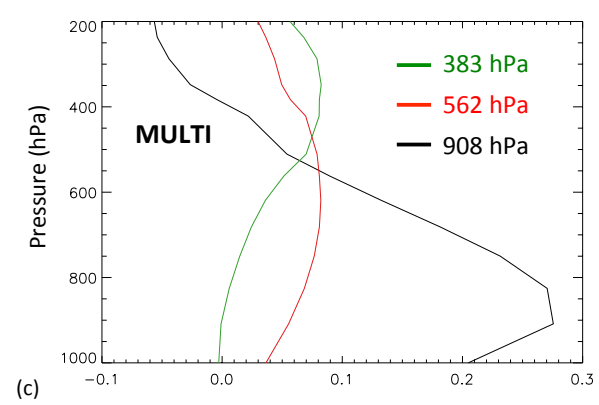

Figure 2. Averaging kernels for the different instrument configurations: (a) TROPOMI column averaging kernel; (b) TES column averaging kernel; (c) multi-spectral averaging kernels at three pressure levels: 908,562 and $383 \mathrm{hPa}$.

retrieval. The TROPOMI retrieval sensitivity is nearly uniform throughout the troposphere, with averaging kernel values close to 1 . The TES retrieval is mostly sensitive to $\mathrm{CH}_{4}$ concentrations in the upper troposphere, with a peak of the column averaging kernel around $300 \mathrm{hPa}$. The multi-spectral profile retrieval shows a distinct signal in the boundary layer, with weaker sensitivities above.

Observation and model transport errors are assumed to be independent and therefore added in quadrature to define the error covariance matrix $\mathbf{R}$ in Eq. (1). Observational error standard deviations for TROPOMI $X_{\mathrm{CH}_{4}}$ columns are uniformly set to $12 \mathrm{ppb}$, within the range of values reported for GOSAT in Parker et al. (2011). For the TES retrievals, the profile error covariance matrix is averaged vertically using pressure-weighted functions to obtain $X_{\mathrm{CH}_{4}}$ column errors, as described in Connor et al. (2008). This results in a $0.5-2 \%$ (or 10-40 ppb) standard error deviation for the TES columns
(Worden et al., 2012). For the multi-spectral retrievals, a vertically resolved error covariance matrix is used. The error covariance for the multi-spectral retrieval is derived along with the averaging kernel using the approach described in Fu et al. (2013) and references therein. The Jacobians for $\mathrm{CH}_{4}$ and other trace gases affecting the observed radiances, from the near-IR and thermal IR, are combined along with noise estimates for both spectral regions that are based on TES and GOSAT radiances. Because we assume that interferences such as albedo, emissivity, and $\mathrm{H}_{2} \mathrm{O}$ are jointly estimated, the uncertainties from these interferences are also included in the resulting observation error matrix. The resulting pressure-weighted column $X_{\mathrm{CH}_{4}}$ error standard deviation is similar to the one obtained for GOSAT retrievals ( $\sim 12 \mathrm{ppb})$.

As shown by Locatelli et al. (2013), taking into account transport errors is critical in order to mitigate uncertainties in the inversion, since neglecting them can lead to discrepancies in the posterior estimates of more than $150 \%$ of the prior flux at model grid scale. We estimate model transport error using model-data comparison statistics for North American in situ observations from the NOAA/ESRL surface, tower, and flask network as well as observations from the HIPPO and CalNex measurement campaigns (Turner et al., 2015). Model error standard deviations are set to $46 \mathrm{ppb}$ in the boundary layer and $22 \mathrm{ppb}$ in the free troposphere. Vertical error correlations between simulated concentrations are difficult to quantify with the limited observational sampling available in situ. Transport error correlations between the boundary layer and the free troposphere are assumed to be negligible due to the decoupling of the physical processes between those two regions. However, within both the boundary layer and the free troposphere, a model error correlation of one is assumed between all altitude levels, which is a conservative (pessimistic) assumption. Our gradient-based estimates of the inverse Hessian matrix involve generating random perturbations that follow the observational error statistics (see Sect. 2.1). For the multi-spectral configuration, a singular value decomposition (SVD) is first performed on the vertically resolved matrix $\mathbf{R}$ in order to generate independent perturbations (e.g., Bousserez et al., 2015).

In order to assess the relative impact of measurement sensitivity versus spatiotemporal sampling on the $\mathrm{CH}_{4}$ emission constraints, both LEO and GEO orbit configurations are considered in our study. The LEO orbit configuration approximately follows TROPOMI's sun-synchronous polar orbit with an Equator overpass local time of 14:00 and daily global coverage with a footprint area of $\sim 7 \times 7 \mathrm{~km}^{2}$. The GEO configuration corresponds to hourly observations over North America from 10 to $60^{\circ} \mathrm{N}$. The GEO footprint considered is $\sim 4 \mathrm{~km}$, i.e., much finer than the GEOS-Chem resolution used $(\sim 50 \mathrm{~km})$. For both LEO and GEO configurations, observations are therefore averaged together within each GEOS-Chem grid cell and the instrument error standard 

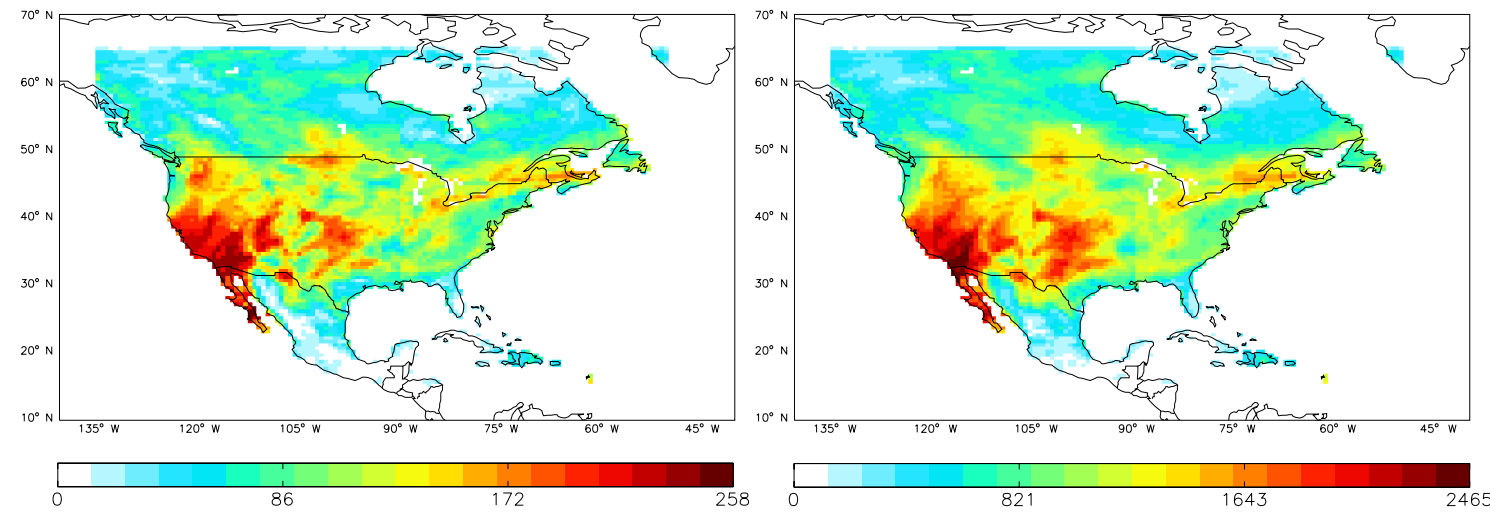

Figure 3. Density of satellite observations (grid cell ${ }^{-1}$ week $^{-1}$ ) for LEO (left) and GEO (right) orbits for the nested North America domain $\left(0.5^{\circ} \times 0.7^{\circ}\right)$ and for the period $1-8$ July 2008 .

deviation is reduced by multiplying it by the square root of the number of observations.

Finally, contamination by clouds is taken into account for each grid cell by removing a fraction of the total number of observations within that cell that corresponds to the GEOS-5 cloud fraction. The resulting spatial distribution of the observational data density for each satellite configuration (LEO or GEO) is shown in Fig. 3.

\section{Results}

In the following experiments, we consider the inversion of 30-, 7-, and 3-day grid-scale emission scaling factors over North America. In particular, this means that the spatiotemporal variability of the methane fluxes (e.g., diurnal cycle and spatial distribution) within each time window is assumed to be known, and only its magnitude is adjusted. The information content of the inversion is analyzed for four different observational systems:

- a TROPOMI instrument onboard a low-Earth orbit platform (TROPOMI_LEO);

- a TROPOMI instrument onboard a geostationary orbit platform (TROPOMI_GEO);

- a TES-like instrument onboard a geostationary orbit platform (TES_GEO);

- a multi-spectral instrument onboard a geostationary orbit platform (MULTI_GEO).

\subsection{Error reduction of optimized methane emissions}

Figures 4, 5, and 6 show the relative error variance reduction in the emission scaling factors for 30-, 7-, and 3-day inversions, respectively, for each of the observational configurations described above. The DOF, which quantifies the number of pieces of information independently constrained by the observations, is also indicated. For the monthly inversion, the TROPOMI_LEO, TROPOMI_GEO, and MULTI_GEO configurations show error variance reductions close to $100 \%$ for sparse hotspots over the continent, in particular in the Los Angeles basin, the central US, the Toronto urban area, the Appalachian Mountains, and the northeastern US. The TES_GEO configuration still shows significant observational constraints in those locations, with error variance reductions $>70 \%$. However, overall the error variance reductions afforded by using a TES-like instrument in geostationary orbit are much smaller than the one obtained from a TROPOMIlike or multi-spectral instrument. In particular, the DOF for the TES_GEO configuration (164) is about half that of the TROPOMI_LEO configuration (298). This demonstrates that using measurements with significant sensitivities to lowertropospheric concentrations is critical to obtaining surface flux information, even in a geostationary framework with high-frequency temporal sampling. The advantage of the GEO over the LEO configuration is more pronounced when smaller emission timescales are constrained (weekly, 3-day). In particular, the DOF for TROPOMI_LEO varies from 88 to $43 \%$ of the DOF for TROPOMI_GEO between the monthly and 3-day inversions. Similarly, but to a lesser extent, the benefit of a multi-spectral profile observation compared to a TROPOMI-like column measurement is most evident when the temporal resolution of the flux inversion is increased, with a DOF ratio between TROPOMI_GEO and MULTI_GEO varying from 84 to $67 \%$ between the monthly and 3-day inversions.

These results are synthesized in Fig. 7, which shows the relative error variance reduction as a function of emission magnitude, for each observational system and inversion time window. The convergence of the flux constraints provided by the TROPOMI (LEO or GEO) and the multi-spectral GEO instruments is well illustrated by the convergence of the corresponding curves as the temporal scale of the optimization increases from 3 days to 1 month. These results also show that for grid cells with high $\mathrm{CH}_{4}$ emissions (> 


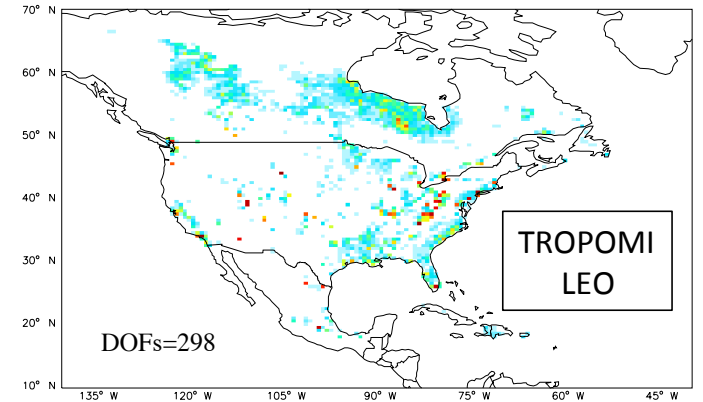

(a)
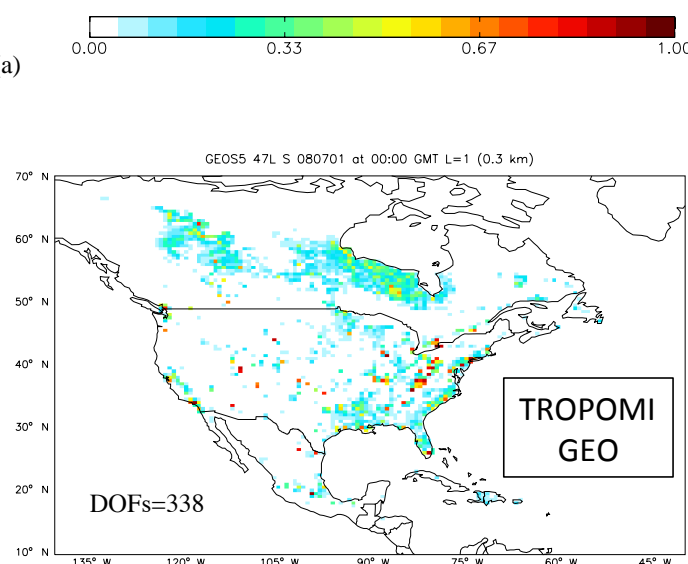

(c)

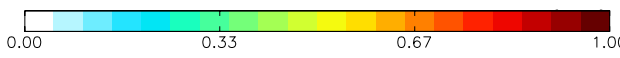

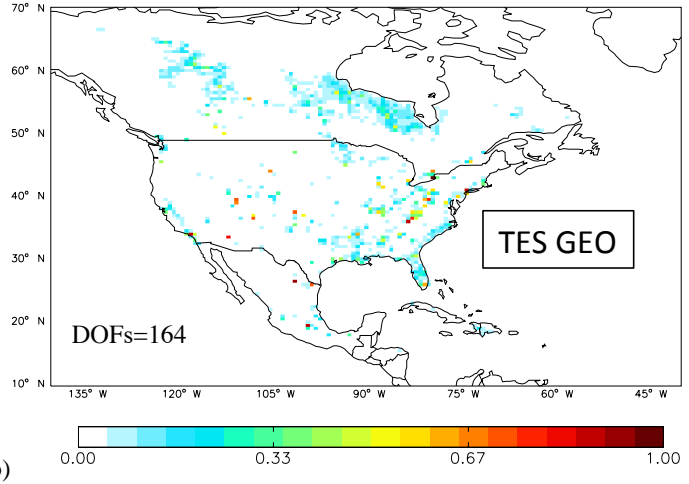

(b)

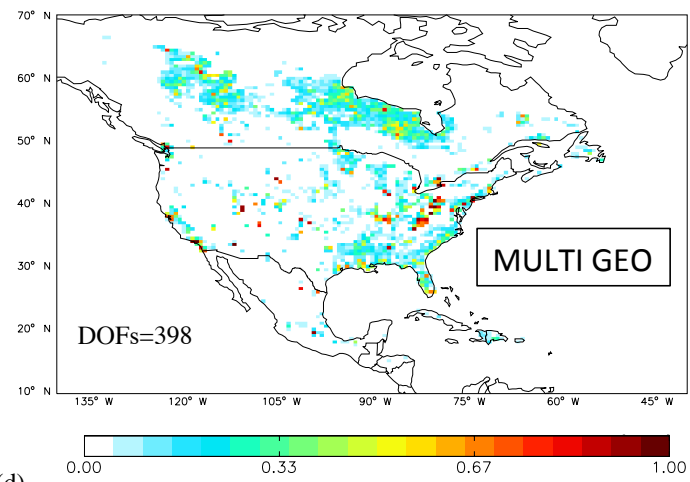

(d)

Figure 4. Relative error variance reduction for a 30-day methane emission optimization (1-30 July 2008) using (a) TROPOMI low-Earth orbit observations (TROPOMI_LEO); (b) GEO-CAPE observations with a TES-like instrument (TES_GEO); (c) GEO-CAPE observations with a TROPOMI-like instrument (TROPOMI_GEO); and (d) GEO-CAPE observations with a multi-spectral instrument (MULTI_GEO). Zero values correspond to emissions with no constraints from observations, while values of one correspond to emissions entirely constrained by observations. The DOF for each inversion, which is the sum of all diagonal elements of the model resolution matrix, is also indicated.

$4 \times 10^{5} \mathrm{~kg} \mathrm{day}^{-1}$ grid $\left.^{-1}\right)$, a multi-spectral instrument in geostationary orbit would reduce prior flux error variances by more than $80 \%$ at timescales as small as 3 days. In particular, this could provide valuable information to monitor the variation of $\mathrm{CH}_{4}$ emission hotspot activities between workweek and weekend. Finally, we note that Turner et al. (2015) obtained a DOF of 39 for a multi-year $\mathrm{CH}_{4}$ flux inversion over North America using GOSAT LEO observations. The much higher DOF (298) obtained for our monthly TROPOMI_LEO inversion clearly demonstrates the impact of spatial sampling when using a TROPOMI LEO configuration, which will provide roughly 2 orders of magnitude more observations than GOSAT. We also note that in Turner et al. (2015), a prior dimension reduction of the inverse problem was performed to enable an analytical computation of the solution with only 369 control vector elements. Although it is claimed that the aggregation scheme used to define the reduced space is designed to account for prior error correlations, the results obtained in Turner et al. (2015) indicate the reduction method is suboptimal (see the interactive discussion of Turner et al., 2015, for more details), which could result in an underestimation of the DOF. On the other hand, in our case neglecting error correlations in the prior inventory may result in an overestimation of the DOF. In the absence of a rigorous methodology to accurately estimate the prior error correlations, the DOFs we derived should therefore be interpreted with caution, but can provide useful insights into the relative magnitude of the constraints afforded by different instruments and orbit configurations. These results also correspond to the limit to which the observational constraints would tend as the effective spatial resolutions of the bottom-up $\mathrm{CH}_{4}$ inventories are increased. In relation to previous works by Turner et al. (2015) and Bocquet et al. (2011), it should also be noted that the gradient-based algorithm used in our study allows us to estimate the DOF of the inversion prior to optimization; this information could therefore be used to objectively determine an appropriate dimension for the inverse problem, upon which specific dimension reduction methods could be devised. 
Table 1. Coordinates of the five locations considered for the rows of the model resolution matrix, with their corresponding emission rate.

\begin{tabular}{lrrr}
\hline Region & $\begin{array}{r}\text { Coordinates } \\
\left(\text { lon, lat }\left(^{\circ}\right)\right)\end{array}$ & $\begin{array}{r}\text { Emission } \\
\left(10^{5} \mathrm{~kg} \mathrm{day}^{-1}(\text { grid cell })^{-1}\right)\end{array}$ & $\begin{array}{r}\text { Emission } \\
\left(10^{5} \mathrm{~kg} \mathrm{day}^{-1} \mathrm{~km}^{-2}\right)\end{array}$ \\
\hline Eastern US & $(-82,38)$ & 399 & 0.12 \\
Central US & $(-104,40)$ & 830 & 0.26 \\
California & $(-117.3,34.5)$ & 595 & 0.26 \\
Western Canadian wetlands & $(-120,61.5)$ & 575 & 0.29 \\
Eastern Canadian wetlands & $(-84.6,52.5)$ & 205 & 0.08 \\
\hline
\end{tabular}
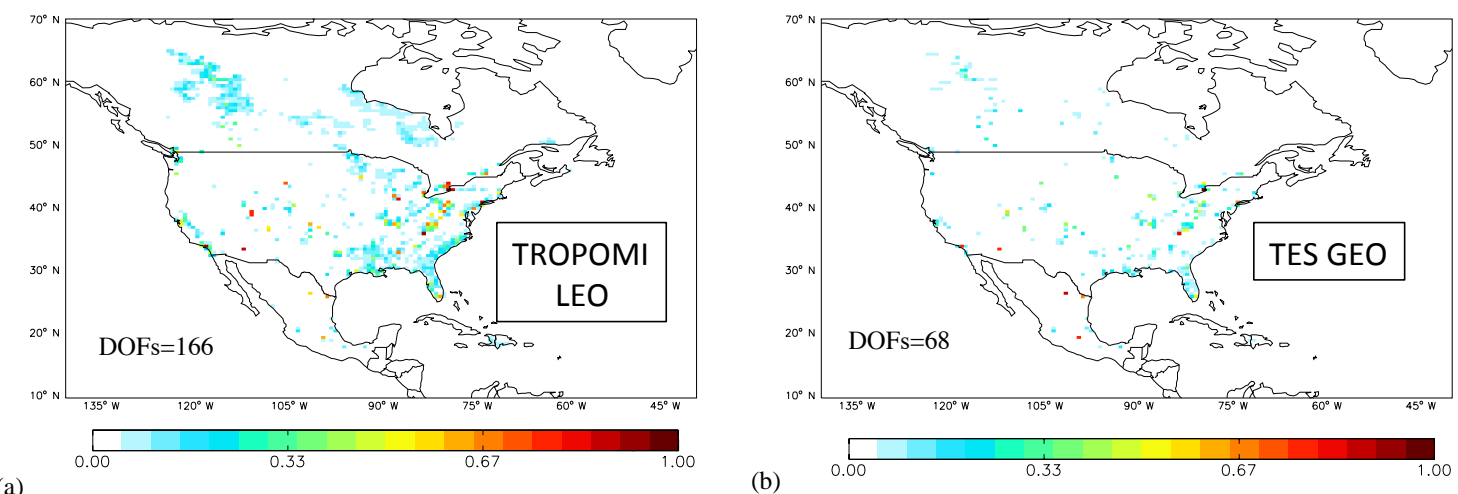

(a)

(b)
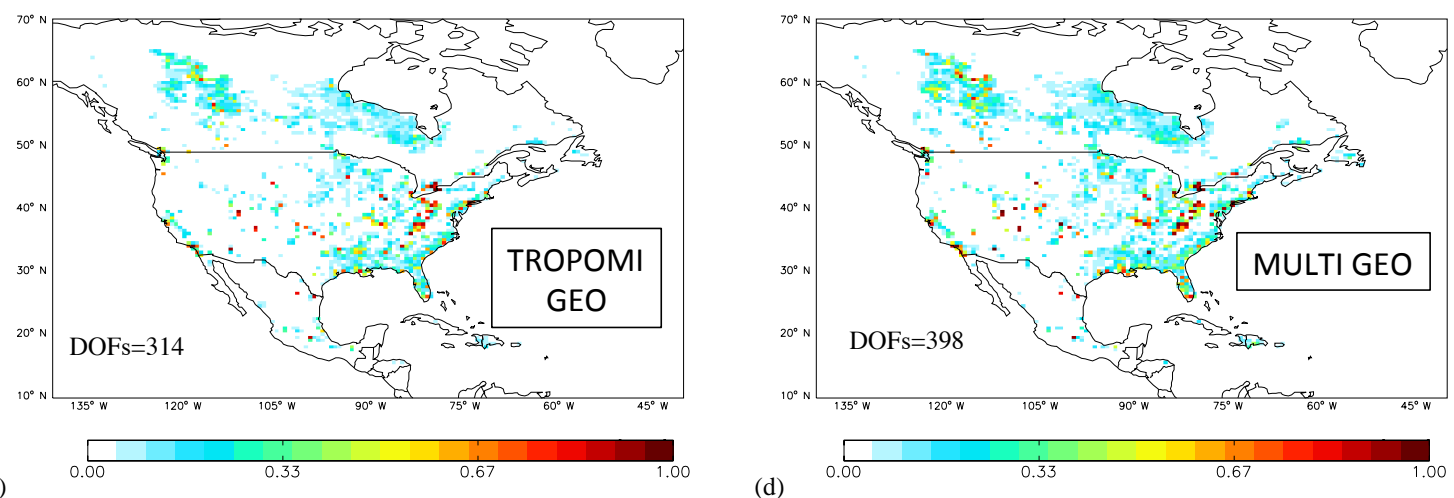

Figure 5. Relative error variance reduction for a 7-day methane emission optimization (1-8 July 2008) using (a) TROPOMI low-Earth orbit observations (TROPOMI_LEO); (b) GEO-CAPE observations with a TES-like instrument (TES_GEO); (c) GEO-CAPE observations with a TROPOMI-like instrument (TROPOMI_GEO); and (d) GEO-CAPE observations with a multi-spectral instrument (MULTI_GEO). Zero values correspond to emissions with no constraints from observations, while values of one correspond to emissions entirely constrained by observations. The DOF for each inversion, which is the sum of all diagonal elements of the model resolution matrix, is also indicated.

\subsection{Spatial resolution of the inversion}

An objective measure of the spatial resolution of the inversion, i.e., the ability of the observational system to constrain grid-scale emissions independently of each other, is provided by the rows of the model resolution matrix (see Eq. 5). Figure 8 shows the model resolution matrix rows of the weekly inversion corresponding to five different locations, chosen to span a range of characteristics, in terms of emissions magnitude and error reduction. For readability, only grid cells included within the largest circle centered on each location and containing values greater than 0.05 are shown. Table 1 summarizes the coordinates and $\mathrm{CH}_{4}$ emissions corresponding to each location. Since the model grid-cell area depends on the latitude, the radiuses of each of the structures shown in Fig. 8 are also summarized in Table 2. Note that the 3day inversion results (not shown) gave similar results to the 1 -week inversion. The gain in spatial resolution of the optimized fluxes when a GEO orbit is used is evident when comparing the TROPOMI_LEO and TROPOMI_GEO results. In particular, Table 2 suggests that for the central US and California regions, the spatial resolution of the independently 

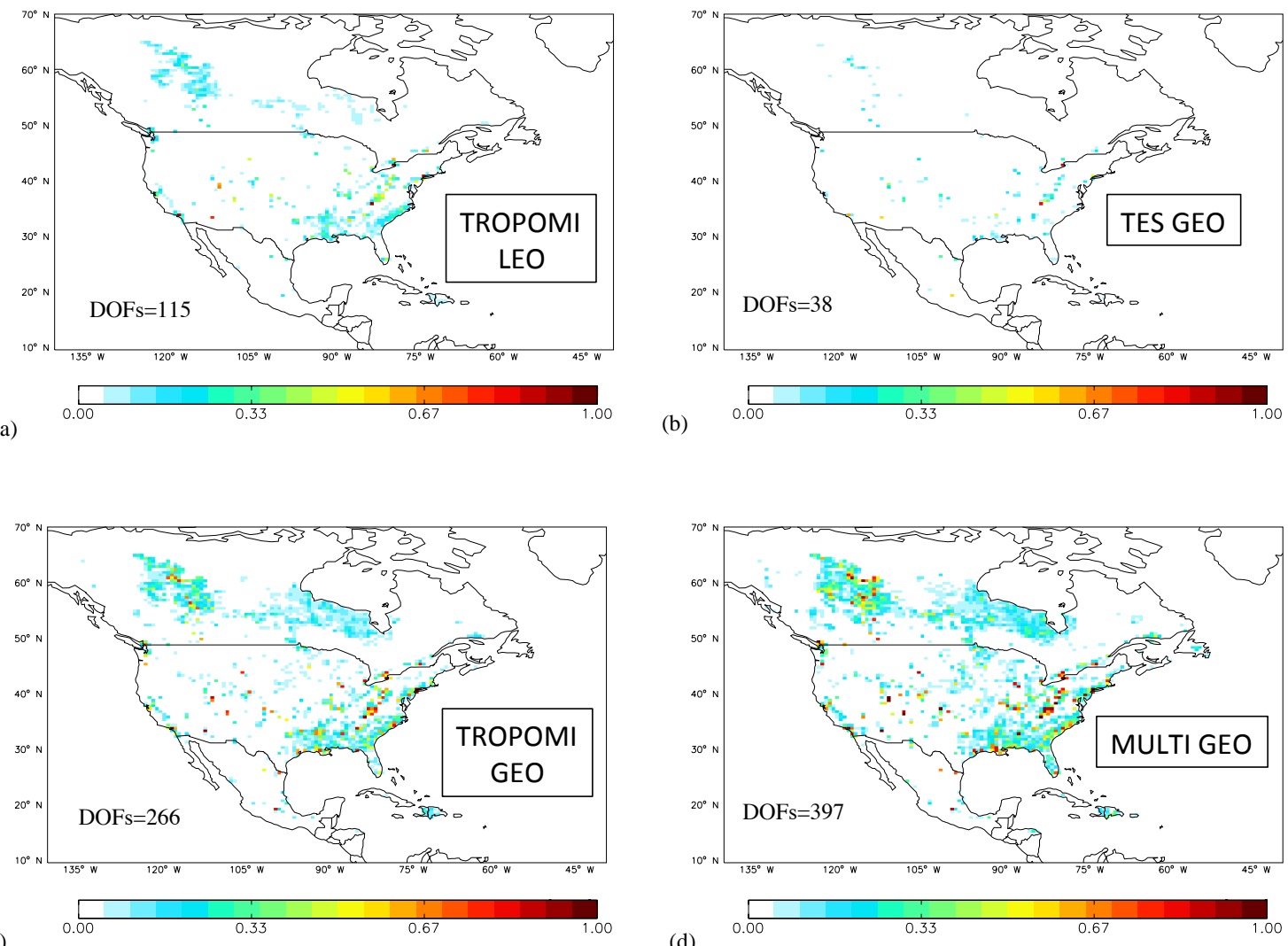

(c)

(d)

Figure 6. Relative error variance reduction for a 3-day methane emission optimization (1-3 July 2008) using (a) TROPOMI low-Earth orbit observations (TROPOMI_LEO); (b) GEO-CAPE observations with a TES-like instrument (TES_GEO); (c) GEO-CAPE observations with a TROPOMI-like instrument (TROPOMI_GEO); and (d) GEO-CAPE observations with a multi-spectral instrument (MULTI_GEO). Zero values correspond to emissions with no constraints from observations, while values of one correspond to emissions entirely constrained by observations. The DOF for each inversion, which is the sum of all diagonal elements of the model resolution matrix, is also indicated.

constrained flux patterns is about 2 times higher in the case of a GEO configuration (radius $\sim 80 \mathrm{~km}$ ) compared to a LEO configuration (radius $\sim 160 \mathrm{~km}$ ). Based on the comparison between the TROPOMI_GEO and MULTI_GEO configurations, the gain in spatial resolution afforded by the use of a multi-spectral instrument appears significant (factor of 2) only over the eastern US region. Note that although the sizes of the flux structures are similar between the TES_GEO and TROPOMI_LEO configurations, the average values of the model resolution matrix row within each structure are significantly higher in the case of TROPOMI_LEO.

\subsection{Impact of boundary and initial conditions uncertainties}

Boundary and initial conditions used in the forward transport model contain errors. Therefore, any consistent flux inversion system should jointly optimize the fluxes, initial state and boundary conditions. However, in practice, many studies overlook this issue and optimize those quantities separately (e.g., Basu et al., 2013; Deng et al., 2014). In the latter case, a flux-only inversion is performed with initial and boundary conditions that are effectively assumed perfectly known. It is therefore of interest to estimate the impact of errors in the initial and boundary conditions on the optimized fluxes. Figure 9 shows the perturbations in the optimized emission scaling factors for the weekly inversion resulting from random Gaussian perturbations of the boundary conditions with standard deviation $16 \mathrm{ppb}$. The choice for the standard error of the noise is based on model-data comparisons from the HIAPER Pole-to-Pole Observations (HIPPO) experiment (Turner et al., 2015), which consists in extensive aircraft measurements throughout the troposphere over the Pacific Ocean. Only weekly inversion results are shown here, so that enough constraints are obtained for all observational configurations while keeping the computational cost of the inversions manageable.

For all configurations, the results show scaling factor perturbations throughout the North America domain, although they are less pronounced over the eastern US due to the dominant westerly propagation of the boundary condition perturbations into the domain. The TES_GEO and TROPOMI_GEO configurations show similar sensitivities of 
Table 2. Coordinates of the five locations considered for the rows of the model resolution matrix and approximate radius of influence of neighboring grid cells (see text), for each satellite configuration and a weekly methane flux inversion.

\begin{tabular}{lrrrrr}
\hline Region & $\begin{array}{r}\text { Coordinates } \\
\left(\text { lon, lat }\left({ }^{\circ}\right)\right)\end{array}$ & $\begin{array}{r}\text { TES_GEO } \\
\text { Radius }(\mathrm{km})\end{array}$ & $\begin{array}{r}\text { TROPOMI_LEO } \\
\text { Radius }(\mathrm{km})\end{array}$ & $\begin{array}{r}\text { TROPOMI_GEO } \\
\text { Radius }(\mathrm{km})\end{array}$ & $\begin{array}{r}\text { MULTI_GEO } \\
\text { Radius }(\mathrm{km})\end{array}$ \\
\hline Eastern US & $(-82,38)$ & 160 & 160 & 160 & 80 \\
Central US & $(-104,40)$ & 79 & 158 & 79 & 79 \\
California & $(-117.3,34.5)$ & 164 & 164 & 82 & 82 \\
Western Canadian wetlands & $(-120,61.5)$ & 130 & 196 & 131 & 196 \\
Eastern Canadian wetlands & $(-84.6,52.5)$ & 283 & 213 & 142 & 142 \\
\hline
\end{tabular}

(a)
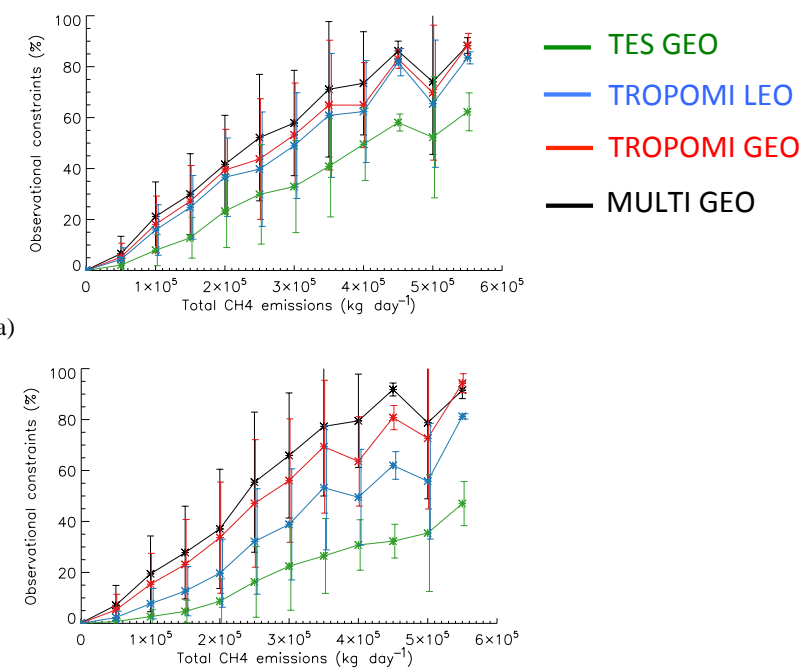

(b)

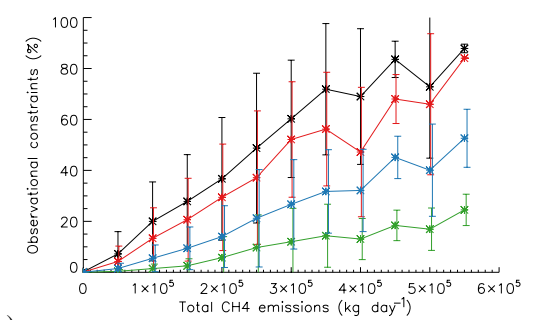

(c)

Figure 7. Relative error variance reduction as a function of methane emission magnitude for a (a) 30-day (1-30 July 2008), (b) 7-day (1-8 July 2008), and (c) 3-day (1-4 July 2008) inversion. Blue: TROPOMI low-Earth orbit observations (TROPOMI_LEO); green: GEO-CAPE observations with a TES-like instrument (TES_GEO); red: GEO-CAPE observations with a TROPOMI-like instrument (TROPOMI_GEO); black: GEO-CAPE observations with a multi-spectral instrument (MULTI_GEO). Results for a 3-day MULTI_GEO inversion are also shown in purple (top). The vertical bars indicate the standard deviation of observational constraints within each bin.

the optimized scaling factors to boundary conditions, with large areas characterized by perturbations between 10 and $50 \%$, and with impacts greater than $50 \%$ locally. In comparison, the TROPOMI_GEO configuration shows smaller sensitivities to boundary conditions, with perturbations generally smaller than $30 \%$. The MULTI_GEO results are in contrast to the other configurations, with most scaling factor perturbations being smaller than $5 \%$.

The differences between the sensitivities of the optimized fluxes to boundary conditions for different observational systems are driven by two factors: (1) the sensitivity of the observations to the underlying fluxes (defined by the operator $H$ ) and (2) the model-data mismatch (i.e., $H(\boldsymbol{x})-\boldsymbol{y})$ ). This can be seen, e.g., by considering the observational term in the gradient formula of Eq. (2). Formally, a perturbation of the boundary conditions will translate into a corresponding perturbation of the observations $(\mathbf{y})$ in the model-data mismatch, which is propagated into flux scaling factor perturbations through the adjoint matrix of sensitivities $\left(\mathbf{H}^{T}\right)$. The effect of (1) is clearly seen when comparing the TROPOMI_GEO and TROPOMI_LEO results, the higher temporal frequency of the geostationary observations providing higher sensitivity to the fluxes. The effect of (2) is best illustrated by comparing the TROPOMI_GEO and MULTI_GEO results. Indeed, since the multi-spectral measurements allow for distinguishing boundary layer from free tropospheric $\mathrm{CH}_{4}$ concentrations, and given the uniform $(\sim 1)$ sensitivity of the TROPOMI column measurements throughout the troposphere (see Fig. 2), the boundary layer model-data mismatch (MULTI_GEO) is much smaller than the column model-data mismatch (TROPOMI_GEO), which results in much higher flux adjustments for the TROPOMI_GEO configuration.

The same analysis applies to the sensitivities of the optimized fluxes to initial conditions, which are shown in Fig. 10. Here the $\mathrm{CH}_{4}$ 3-D initial concentrations were perturbed with random Gaussian noises of standard deviation 46 and $22 \mathrm{ppb}$ in the boundary layer and the free troposphere, respectively, based on model-data comparisons with NOAA flasks, tall tower, and aircraft measurements over North America (Turner et al., 2015). In the case of initial conditions, as opposed to boundary conditions, the forcing perturbations are applied only once at the beginning of the inversion window, which results in the signal being quickly diluted and therefore in smaller impacts on the optimized fluxes. The TROPOMI_GEO configuration, which combines 


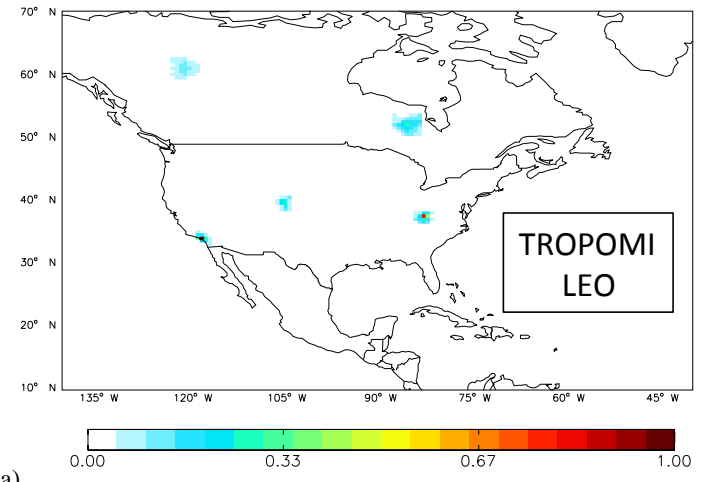

(a)

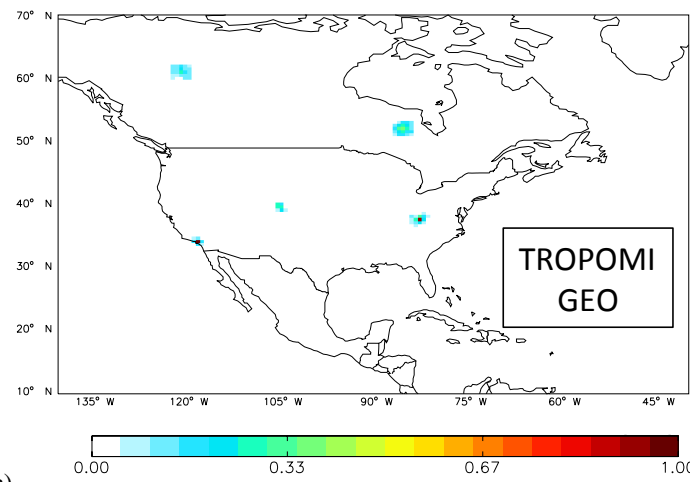

(b)
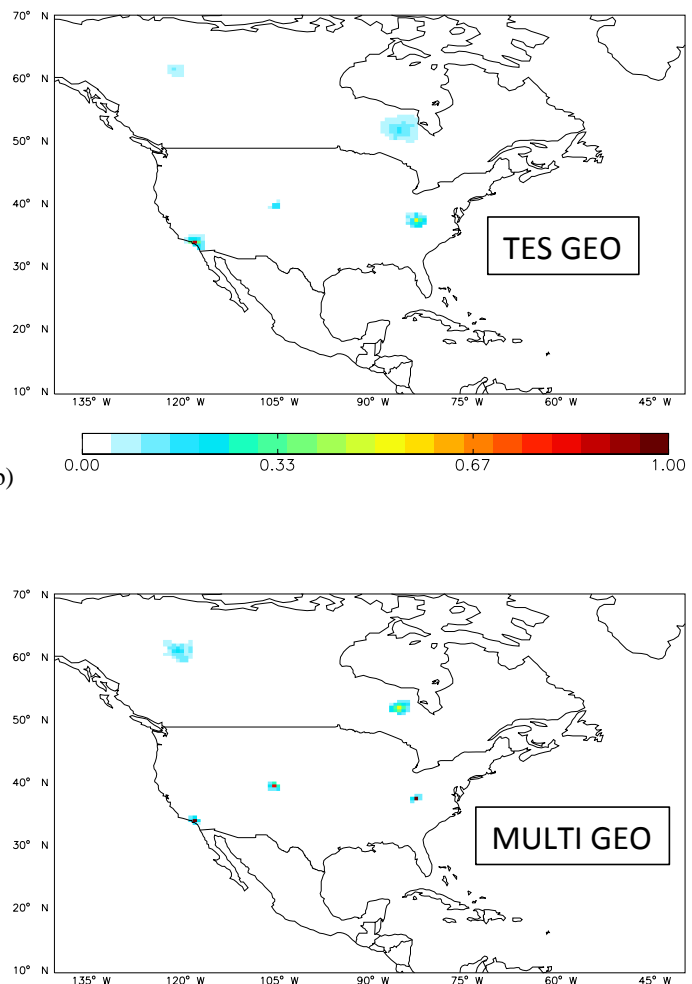

(d)

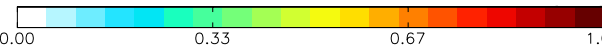

Figure 8. Rows of the model resolution matrix (unitless) for five locations for a 7-day inversion (1-8 July 2008), using (a) TROPOMI low-Earth orbit observations (TROPOMI_LEO); (b) GEO-CAPE observations with a TES-like instrument (TES_GEO); (c) GEO-CAPE observations with a TROPOMI-like instrument (TROPOMI_GEO); and (d) GEO-CAPE observations with a multi-spectral instrument (MULTI_GEO). Coordinates of the five locations considered are reported in Table 1 and approximately correspond to the peak value of each structure on the maps.

significant sensitivities to $\mathrm{CH}_{4}$ concentrations throughout the troposphere with high-frequency measurements, is most sensitive to initial condition perturbations, with up to $30 \%$ variability in the optimized scaling factors. The TROPOMI_LEO and TES_GEO configurations show comparable sensitivities, with scaling factor perturbations generally smaller than $10 \%$. Similarly to the boundary condition case, initial condition sensitivities associated with the MULTI_GEO configuration are about 1 order of magnitude smaller than other configurations, with scaling factor perturbations generally smaller than $3 \%$. These results show that although the advantage of a multi-spectral instrument in terms of spatiotemporal constraints on the fluxes becomes significant only for timescales smaller than a week, there is still a clear benefit in using this configuration to mitigate the impact of uncertainties in boundary and initial conditions on the inversion, even when optimizing fluxes at coarser temporal resolution (e.g., weekly or monthly).

\section{Conclusions}

In this paper we evaluated top-down constraints on methane emissions in North America provided by future potential geostationary (GEO-CAPE) and planned low-Earth orbit (TROPOMI) remote-sensing observation missions. For the first time, a grid-scale estimate of the information content of a high resolution inversion $\left(0.5^{\circ} \times 0.7^{\circ}\right.$ over North America) in a 4D-Var inversion framework has been performed using an efficient stochastic algorithm. In particular, this allowed us to compute both the relative error reductions and the spatial correlations between observational constraints in the inversion. Instrument configurations corresponding to TIR and SWIR methane retrievals (TES-like and TROPOMI, respectively), as well as a potential future multi-spectral retrieval, were considered. This allowed us to assess the relative importance of the vertical sensitivity of the measurement versus the spatiotemporal resolution of the sampling (GEO versus LEO) in methane flux inversions.

We found that a GEO configuration provides significant benefits over the future TROPOMI LEO products in terms 


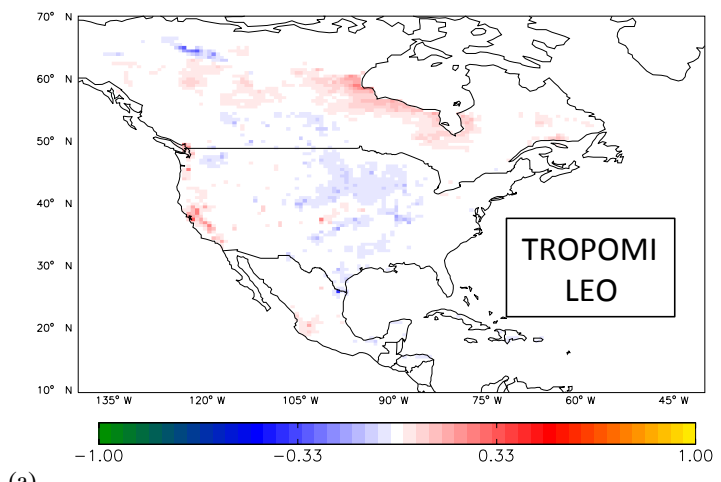

(a)

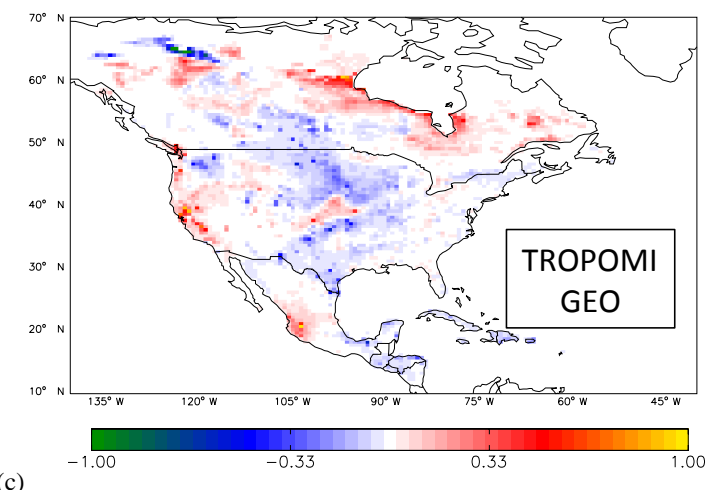

(b)
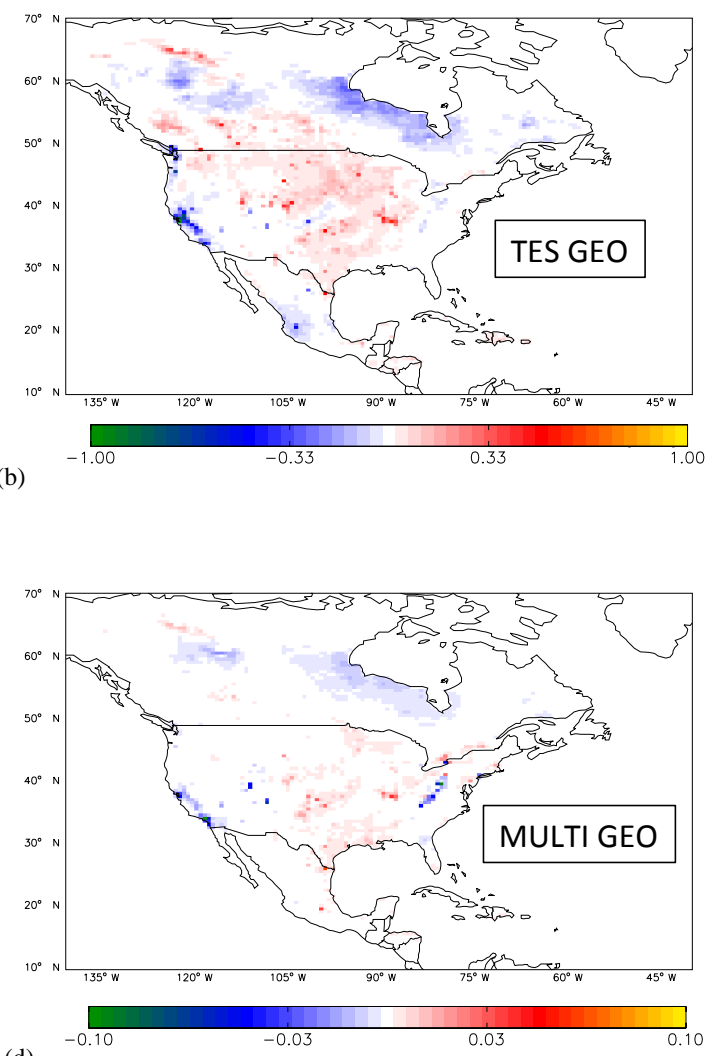

(d)

Figure 9. Sensitivity of the optimized emission scaling factors to uncertainties in boundary conditions for a 7-day inversion (1-8 July 2008), using (a) TROPOMI low-Earth orbit observations (TROPOMI_LEO); (b) GEO-CAPE observations with a TES-like instrument (TES_GEO); (c) GEO-CAPE observations with a TROPOMI-like instrument (TROPOMI_GEO); and (d) GEO-CAPE observations with a multi-spectral instrument (MULTI_GEO). Shown is the impact of perturbations of the boundary condition concentrations with Gaussian distribution $\mathcal{N}(0.16 \mathrm{ppb})$ on the optimized scaling factors. Note the different color scale for the MULTI_GEO configuration.

of error reductions in the optimized fluxes when the targeted timescales are about a week or less. For a 3-day inversion, the number of pieces of information (DOF) independently constrained by the GEO observations is about twice as many as in the case of a LEO configuration (DOF of 266 and 115, respectively). Experiments with TIR GEO and SWIR LEO configurations demonstrated that the high temporal frequency of GEO observations cannot compensate for weak sensitivities of the satellite measurement to boundary layer concentrations, since constraints from a TES-like instrument in GEO orbit correspond to only about half of the information content afforded by a TROPOMI instrument in LEO orbit for a monthly inversion (DOF of 164 and 298, respectively). In a GEO orbit, the benefit of using a multi-spectral instrument compared to a SWIR instrument has been demonstrated for weekly to sub-weekly scale flux constraints, with an increase in the DOF of about $50 \%$ for a 3-day inversion. For the multi-spectral GEO configuration, the information content is similar for a 3-day or a 1-month optimization (DOF of 397 and 398, respectively). Moreover, comparison of our results with those from a recent $\mathrm{CH}_{4}$ inversion study by Turner et al. (2015) suggests that TROPOMI or GEO-CAPE could improve monthly-scale constraints on emissions by about an order of magnitude relative to GOSAT.

Over some local $\mathrm{CH}_{4}$ source hotspots (emissions $>4 \times 10^{5} \mathrm{~kg} \mathrm{day}^{-1}$ ) in the central US, California and eastern US, both SWIR and multi-spectral GEO configurations allow for nearly complete constraints on emissions (error reduction close to $100 \%$ ) at a spatial resolution smaller than $100 \mathrm{~km} \times 100 \mathrm{~km}$. These estimates are optimistic, given the lack of spatial error correlation considered in our prior emissions, which should be addressed in future work, but do reveal the potential spatial resolution provided by the measurements alone.

The sensitivity of the optimized emission scaling factors to uncertainties in initial and boundary conditions has also been assessed by propagating random perturbations of these forcings into the flux estimates. While the flux responses to the boundary and initial condition perturbations can reach 50 and $30 \%$, respectively, in the case of TROPOMI column constraints, they were an order of magnitude lower $(<5 \%)$ in the case of multi-spectral profile observations. 

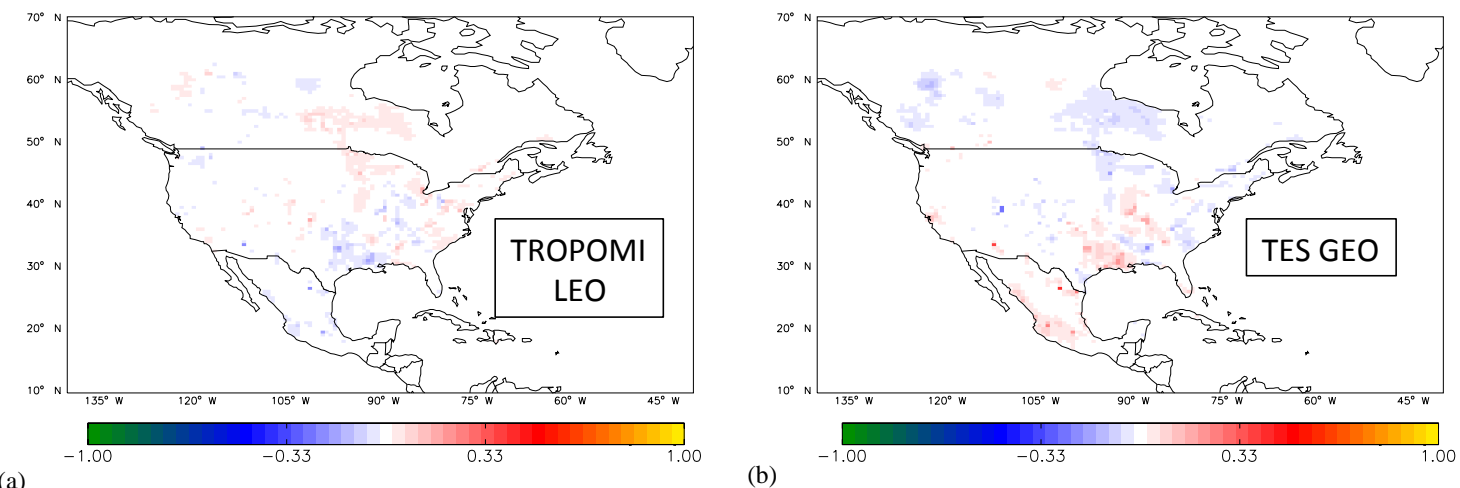

(a)

(b)
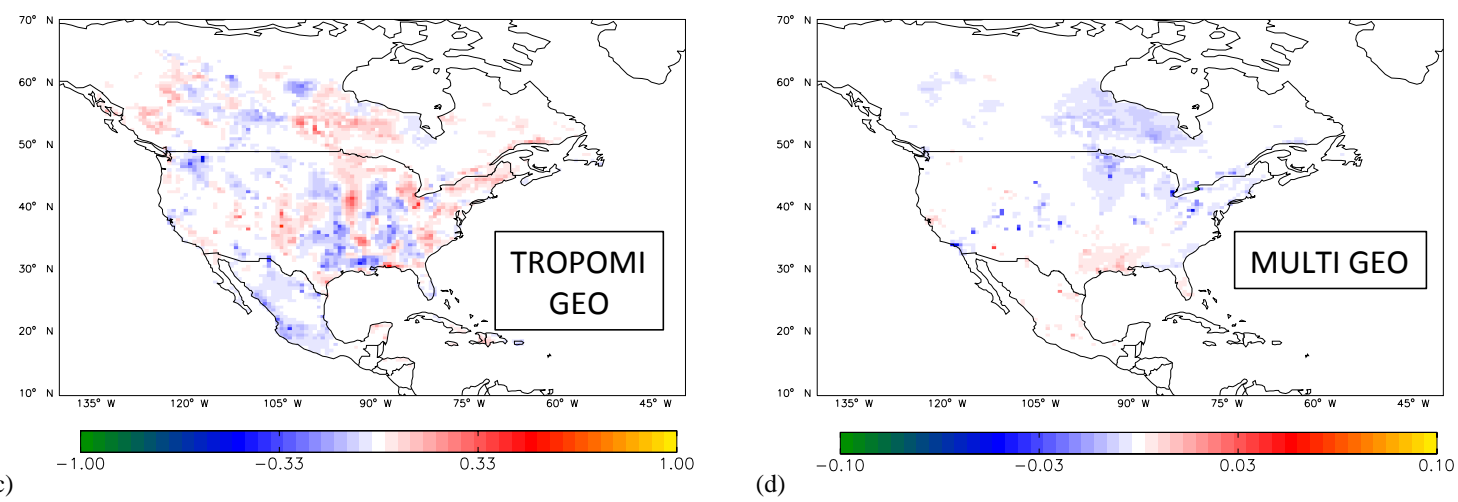

Figure 10. Sensitivity of the optimized emission scaling factors to uncertainties in initial condition concentrations for a 7-day inversion (18 July 2008), using (a) TROPOMI low-Earth orbit observations (TROPOMI_LEO); (b) GEO-CAPE observations with a TES-like instrument (TES_GEO); (c) GEO-CAPE observations with a TROPOMI-like instrument (TROPOMI_GEO); and (d) GEO-CAPE observations with a multi-spectral instrument (MULTI_GEO). Shown is the impact on the optimized emission scaling factors of perturbations of the boundary layer and free troposphere initial $\mathrm{CH}_{4}$ concentrations with Gaussian distributions $\mathcal{N}(0.22 \mathrm{ppb})$ and $\mathcal{N}(0.46 \mathrm{ppb})$, respectively. Note the different color scale for the MULTI_GEO configuration.

With growing concerns about the environmental impacts of $\mathrm{CH}_{4}$ emissions from the oil and gas industry and the urge for better monitoring of the US' $\mathrm{CH}_{4}$ budget, a multi-spectral instrument onboard geostationary orbit would provide a key tool to characterize the variability of the $\mathrm{CH}_{4}$ fluxes at a weekly to sub-weekly timescale, while greatly mitigating the impact of inverse method uncertainties on the optimized fluxes. Moreover, such an observational system would allow for better understanding of the critical role of wetlands in the global methane budget and their impact on climate change (e.g., Bloom et al., 2012; Miller et al., 2014). Further investigations would be needed to quantify the sensitivity of these results to the choice of the reference $\mathrm{CH}_{4}$ emission inventory, since significant discrepancies in the magnitude and spatiotemporal distributions of $\mathrm{CH}_{4}$ sources exist between current bottom-up inventories (Kirschke et al., 2013).

In our study we have neglected prior error correlations in the absence of robust data and methodology to rigorously estimate them. Since error correlations in prior bottom-up inventories nevertheless exist, additional experiments should be performed to test the sensitivity of our information con- tent analysis to different error correlation structures. Likewise, horizontal spatial correlations associated with model and observations errors should be included in future OSSEs in order to obtain more reliable error reduction estimates. We have also performed the inversion using emission scaling factors, which effectively places a hard constraint on the spatial distribution of the emissions - an assumption that warrants further investigations. The robustness of our results against model and observational biases should also be investigated. Finally, following recent studies investigating regional to urban constraints from geostationary remote-sensing instruments (Polonsky et al., 2014; Rayner et al., 2014), it would be interesting to apply the present methodological framework to inversions at much higher spatiotemporal resolution in order to analyze the ability of such observational systems to extract information at spatial scales of only a few $\mathrm{km}^{2}$. 
Acknowledgements. This project was supported by NASA GEOCAPE Science Team grant NNX14AH02G and NOAA grant NA14OAR4310136. This work utilized the Janus supercomputer, which is supported by the National Science Foundation (award number CNS-0 821 794) and the University of Colorado Boulder. The Janus supercomputer is a joint effort of the University of Colorado Boulder, the University of Colorado Denver and the National Center for Atmospheric Research. Alexander J. Turner was supported by a Department of Energy (DOE) Computational Science Graduate Fellowship (CSGF). Part of this research was carried out at the Jet Propulsion Laboratory, California Institute of Technology, under a contract with the National Aeronautics and Space Administration.

Edited by: M. Palm

\section{References}

Basu, S., Guerlet, S., Butz, A., Houweling, S., Hasekamp, O., Aben, I., Krummel, P., Steele, P., Langenfelds, R., Torn, M., Biraud, S., Stephens, B., Andrews, A., and Worthy, D.: Global $\mathrm{CO}_{2}$ fluxes estimated from GOSAT retrievals of total column $\mathrm{CO}_{2}$, Atmos. Chem. Phys., 13, 8695-8717, doi:10.5194/acp-13-86952013, 2013.

Bloom, A. A., Palmer, P. I., Fraser, A., and Reay, D. S.: Seasonal variability of tropical wetland $\mathrm{CH}_{4}$ emissions: the role of the methanogen-available carbon pool, Biogeosciences, 9, 28212830, doi:10.5194/bg-9-2821-2012, 2012.

Bocquet, M., Wu, L., and Chevallier, F.: Bayesian design of control space for optimal assimilation of observations. Part I: Consistent multiscale formalism, Q. J. Roy. Meteor. Soc., 137, 1340-1356, doi:10.1002/qj.837, 2011.

Bousserez, N., Henze, D. K., Perkins, A., Bowman, K. W., Lee, M., Liu, J., Deng, F., and Jones, D. B. A.: Improved analysiserror covariance matrix for high-dimensional variational inversions: application to source estimation using a 3-D atmospheric transport model, Q. J. Roy. Meteor. Soc., 141, 1906-1921, doi:10.1002/qj.2495, 2015.

Butz, A., Hasekamp, O. P., Frankenberg, C., Vidot, J., and Aben, I.: $\mathrm{CH}_{4}$ retrievals from space-based solar backscatter measurements: Performance evaluation against simulated aerosol and cirrus loaded scenes, J. Geophys. Res., 115, D24302, doi:10.1029/2010JD014514, 2010.

Caulton, D. R., Shepson, P. B., Santoro, R. L., Sparks, J. P., Howarth, R. W., Ingraffea, A. R., Cambaliza, M. O., Sweeney, C., Karion, A., Davis, K. J., Stirm, B. H., Montzka, S. A., and Miller, B. R.: Toward a better understanding and quantification of methane emissions from shale gas development, P. Natl. Acad. Sci. USA, 111, 6237-6242, 2014.

Chance, K., Liu, X., Suleiman, R. M., Flittner, D. E., Al-Saadi, J., and Janz, S. J.: Tropospheric emissions: monitoring of pollution (TEMPO), Proc. SPIE 8866, Earth Observing Systems XVIII, 88660D (23 September 2013), doi:10.1117/12.2024479, 2013.

Chevallier, F., Bréon, F. M., and Rayner, P. J.: Contribution of the Orbiting Carbon Observatory to the estimation of $\mathrm{CO}_{2}$ sources and sinks: Theoretical study in a variational data assimilation framework, J. Geophys. Res.-Atmos., 112, 2156-2202, 2007.
Connor, B. J., Boesch, H., Toon, G., Sen, B., Miller, C., and Crisp, D.: Orbiting Carbon Observatory: Inverse method and prospective error analysis, J. Geophys. Res.-Atmos., 113, D05305, doi:10.1029/2006JD008336, 2008.

Cressot, C., Chevallier, F., Bousquet, P., Crevoisier, C., Dlugokencky, E. J., A., Fortems-Cheiney, A., Frankenberg, C., Parker, R., Pison, I., Scheepmaker, R. A., Montzka, S. A., Montzka, S. A., Krummel, P. B., Steele, L. P., and Langenfelds, R. L.: On the consistency between global and regional methane emissions inferred from SCIAMACHY, TANSO-FTS, IASI and surface measurements, Atmos. Chem. Phys., 14, 577592, doi:10.5194/acp-14-577-2014, 2014.

Deng, F., Jones, D. B. A., Henze, D. K., Bousserez, N., Bowman, K. W., Fisher, J. B., Nassar, R., O’Dell, C., Wunch, D., Wennberg, P. O., Kort, E. A., Wofsy, S. C., Blumenstock, T., Deutscher, N. M., Griffith, D. W. T., Hase, F., Heikkinen, P., Sherlock, V., Strong, K., Sussmann, R., and Warneke, T.: Inferring regional sources and sinks of atmospheric $\mathrm{CO}_{2}$ from GOSAT $\mathrm{XCO}_{2}$ data, Atmos. Chem. Phys., 14, 3703-3727, doi:10.5194/acp-14-37032014, 2014.

Dlugokencky, E. J., Nisbet, E. G., Fisher, R., and Lowry, D.: Global atmospheric methane: budget, changes and dangers, Philos. T. R. Soc. A, 369, 2058-2072, 2011.

European Commission: Emission Database for Global Atmospheric Research (EDGAR), release version 4.2, Tech. rep., Joint Research Centre (JRC)/Netherlands Environmental Assessment Agency (PBL), available at: http://edgar.jrc.ec.europa.eu (last access: 1 December 2014), 2011.

Fiore, A. M., Jacob, D. J., Field, B. D., Streets, D. G., Fernandes, S. D., and Jang, C.: Linking ozone pollution and climate change: the case for controlling methane, Geophys. Res. Lett., 29, 25-1, 2002.

Fiore, A. M., West, J. J., Horowitz, L. W., Naik, V., and Schwarzkopf, M. D.: Characterizing the tropospheric ozone response to methane emission controls and the benefits to climate and air quality, J. Geophys. Res.-Atmos., 113, 1984-2012, 2008.

Fishman, J., Iraci, L., Al-Saadi, J., Chance, K., Chavez, F., Chin, M., Coble, P., Davis, C., DiGiacomo, P., Edwards, D., Eldering, L., Goes, J., Herman, J., Hu, C., Jacob, D. J., Jordan, C., Kawa, S. R., Key, R., Liu, X., Lohrenz, S., Mannino, A., Natraj, V., Neil, D., Neu, J., Newchruch, M., Pickering, K., Salisbury, J., Sosik, H., Subramaniam, A., Tzortziou, M., Wang, J., and Wang, M.: The United States' next generation of atmospheric composition and coastal ecosystem measurements: NASA's Geostationary Coastal and Air Pollution Events (GEO-CAPE) Mission, B. Am. Meteorol. Soc., 93, 1547-1566, 2012.

Fu, D., Worden, J. R., Liu, X., Kulawik, S. S., Bowman, K. W., and Natraj, V.: Characterization of ozone profiles derived from Aura TES and OMI radiances, Atmos. Chem. Phys., 13, 3445-3462, doi:10.5194/acp-13-3445-2013, 2013.

Fung, I., John, J., Lerner, J., Matthews, E., Prather, M., Steele, L., and Fraser, P.: Three-dimensional model synthesis of the global methane cycle, J. Geophys. Res.-Atmos., 96, 13033-13065, 1991.

Gazovic, M., Kutzbach, L., Schreiber, P., Wille, C., and Wilmking, M.: Diurnal dynamics of $\mathrm{CH}_{4}$ from a boreal peatland during snowmelt, Tellus B, 62, 133-139, 2010. 
Kaplan, J. O.: Wetlands at the Last Glacial Maximum: distribution and methane emissions, Geophys. Res. Lett., 29, 3-1-3-4, doi:10.1029/2001GL013366, 2002.

Karion, A., Sweeney, C., Pétron, G., Frost, G., Michael Hardesty, R., Kofler, J., Miller, B. R., Newberger, T., Wolter, S., Banta, R., Brewer, A., Dlugokencky, E., Lang, P., Montzka, S. A., Schnell, R., Tans, P., Trainer, M., Zamora, R., and Conley, S.: Methane emissions estimate from airborne measurements over a western United States natural gas field, Geophys. Res. Lett., 40, 4393-4397, 2013.

Katzenstein, A. S., Doezema, L. A., Simpson, I. J., Blake, D. R., and Rowland, F. S.: Extensive regional atmospheric hydrocarbon pollution in the southwestern United States, P. Natl. Acad. Sci. USA, 100, 11975-11979, 2003.

Kirschke, S., Bousquet, P., Ciais, P., Saunois, M., Canadell, J. G., Dlugokencky, E. J., Bergamaschi, P., Bergmann, D., Blake, D. P., Bruhwiler, L., Cameron-Smith, P., Castaldi, P., Chevallier, F., Feng, L., Fraser, A., Heimann, M., Hodson, E. L., Houweling, S., Josse, B., Fraser, P. J., Krummel, P. B., Lamarque, J. F., Langenfelds, R. L., Le Quere, C., Naik, V., O'Doherty, S., Palmer, P. I., Pison, I., Plummer, D., Poulter, B., Prinn, R. G., Rigby, M., Ringeval, B., Santini, M., Schmidt, M., Shindell, D. T., Simpson, I. J., Spahni, R., Steele, L. P., Strode, S. A., Sudo, K., Szopa, S., van der Werf, G. R., Voulgarakis, A., van Weele, M., Weiss, R. F., Williams, J. E., and Zen, G.: Three decades of global methane sources and sinks, Nat. Geosci., 6, 813-823, 2013.

Kort, E. A., Eluszkiewicz, J., Stephens, B. B., Miller, J. B., Gerbig, C., Nehrkorn, T., Daube, B. C., Kaplan, J. O., Houweling, S., and Wofsy, S. C.: Emissions of $\mathrm{CH}_{4}$ and $\mathrm{N}_{2} \mathrm{O}$ over the United States and Canada based on a receptor-oriented modeling framework and COBRA-NA atmospheric observations, Geophys. Res. Lett., 35, L18808, doi:10.1029/2008GL034031, 2008.

Kulawik, S. S., Worden, J., Eldering, A., Bowman, K., Gunson, M., Osterman, G. B., Zhang, L., Clough, S., Shephard, M. W., and Beer, R.: Implementation of cloud retrievals for Tropospheric Emission Spectrometer (TES) atmospheric retrievals: part 1. Description and characterization of errors on trace gas retrievals, J. Geophys. Res., 111, D24204, doi:10.1029/2005JD006733, 2006.

Lions, J. L.: Optimal Control of Systems Governed by Partial Differential Equations, Springer-Verlag, Berlin, 1971.

Liu, J., Bowman, K., Lee, M., Henze, D. K., Bousserez, N., Brix, H., Collatz, G., Menemenlis, D., Ott, L., Pawson, S., Jones, D., and Nassar, R.: Carbon monitoring system flux estimation and attribution: impact of ACOS-GOSAT $\mathrm{XCO}_{2}$ sampling on the inference of terrestrial biospheric sources and sinks, Tellus B, 66, 22486, doi:10.3402/tellusb.v66.22486, 2014

Locatelli, R., Bousquet, P., Chevallier, F., Fortems-Cheney, A., Szopa, S., Saunois, M., Agusti-Panareda, A., Bergmann, D., Bian, H., Cameron-Smith, P., Chipperfield, M. P., Gloor, E., Houweling, S., Kawa, S. R., Krol, M., Patra, P. K., Prinn, R. G., Rigby, M., Saito, R., and Wilson, C.: Impact of transport model errors on the global and regional methane emissions estimated by inverse modelling, Atmos. Chem. Phys., 13, 9917-9937, doi:10.5194/acp-13-9917-2013, 2013.

Meirink, J. F., Bergamaschi, P., and Krol, M. C.: Fourdimensional variational data assimilation for inverse modelling of atmospheric methane emissions: method and comparison with synthesis inversion, Atmos. Chem. Phys., 8, 6341-6353, doi:10.5194/acp-8-6341-2008, 2008.
Miller, S. M., Wofsy, S. C., Michalak, A. M., Kort, E. A., Andrews, A. E., Biraud, S. C., Dlugokencky, E. J., Eluszkiewicz, J., Fischer, M. L., Janssens-Maenhout, G., Miller, B. R., Miller, J. B., Montzkad, S. A., Nehrkornf, T., and Sweene, C.: Anthropogenic emissions of methane in the United States, P. Natl. Acad. Sci. USA, 110, 20018-20022, 2013.

Miller, S. M., Worthy, D. E., Michalak, A. M., Wofsy, S. C., Kort, E. A., Havice, T. C., Andrews, A. E., Dlugokencky, E. J., Kaplan, J. O., Levi, P. J., Tian, H., and Zhang, B.: Observational constraints on the distribution, seasonality, and environmental predictors of North American boreal methane emissions, Global Biogeochem. Cy., 28, 146-160, 2014.

Morin, T. H., Bohrer, G., Naor-Azrieli, L., Mesi, S., Kenny, W. T., Mitsch, W. J., and Schaefer, K. V. R.: The seasonal and diurnal dynamics of methane flux at a created urban wetland, Ecol. Eng., 72, 74-83, 2014.

Myhre, G. and Shindell, D.: Climate Change 2013: The Physical Science Basis, Intergovernmental Panel on Climate Change (IPCC), Chap. 8, Cambridge University Press, 2013.

Parker, R., Boesch, H., Cogan, A., Fraser, A., Feng, L., Palmer, P. I., Messerschmidt, J., Deutscher, N., Griffith, D. W., Notholt, J., Wennberg, P. O., and Wunch, D.: Methane observations from the Greenhouse Gases Observing SATellite: comparisonn to groundbased TCCON data and model calculations, Geophys. Res. Lett., 38, L15807, doi:10.1029/2011GL047871, 2011.

Pickett-Heaps, C. A., Jacob, D. J., Wecht, K. J., Kort, E. A., Wofsy, S. C., Diskin, G. S., Worthy, D. E. J., Kaplan, J. O., Bey, I., and Drevet, J.: Magnitude and seasonality of wetland methane emissions from the Hudson Bay Lowlands (Canada), Atmos. Chem. Phys., 11, 3773-3779, doi:10.5194/acp-11-37732011, 2011.

Polonsky, I. N., O’Brien, D. M., Kumer, J. B., O’Dell, C. W., and the geoCARB Team: Performance of a geostationary mission, geoCARB, to measure $\mathrm{CO}_{2}, \mathrm{CH}_{4}$ and $\mathrm{CO}$ column-averaged concentrations, Atmos. Meas. Tech., 7, 959-981, doi:10.5194/amt7-959-2014, 2014.

Rayner, P. J., Utembe, S. R., and Crowell, S.: Constraining regional greenhouse gas emissions using geostationary concentration measurements: a theoretical study, Atmos. Meas. Tech., 7, 3285-3293, doi:10.5194/amt-7-3285-2014, 2014.

Shindell, D., Kuylenstierna, J. C., Vignati, E., van Dingenen, R., Amann, M., Klimont, Z., Anenberg, S. C., Muller, N., JanssensMaenhout, G., Raes, F., Schwartz, J., Faluvegi, G., Pozzoli, L., Kupiainen, K., Hoglund-Isaksson, L., Emberson, L., Streets, D., Ramanathan, V., Hicks, K., Oanh, N., Milly, G., Williams, M., Demkine, V., and Fowler, D.: Simultaneously mitigating nearterm climate change and improving human health and food security, Science, 335, 183-189, 2012.

Tarantola, A.: Inverse problem theory and methods for model parameter estimation, SIAM, doi:10.1137/1.9780898717921, 2005.

Turner, A. J. and Jacob, D. J.: Balancing aggregation and smoothing errors in inverse models, Atmos. Chem. Phys., 15, 7039-7048, doi:10.5194/acp-15-7039-2015, 2015.

Turner, A. J., Jacob, D. J., Wecht, K. J., Maasakkers, J. D., Lundgren, E., Andrews, A. E., Biraud, S. C., Boesch, H., Bowman, K. W., Deutscher, N. M., Dubey, M. K., Griffith, D. W. T., Hase, F., Kuze, A., Notholt, J., Ohyama, H., Parker, R., Payne, V. H., Sussmann, R., Sweeney, C., Velazco, V. A., Warneke, T., 
Wennberg, P. O., and Wunch, D.: Estimating global and North American methane emissions with high spatial resolution using GOSAT satellite data, Atmos. Chem. Phys., 15, 7049-7069, doi:10.5194/acp-15-7049-2015, 2015.

van der Werf, G. R., Randerson, J. T., Giglio, L., Collatz, G. J., Mu, M., Kasibhatla, P. S., Morton, D. C., DeFries, R. S., Jin, Y., and van Leeuwen, T. T.: Global fire emissions and the contribution of deforestation, savanna, forest, agricultural, and peat fires (1997-2009), Atmos. Chem. Phys., 10, 11707-11735, doi:10.5194/acp-10-11707-2010, 2010.

Wecht, K. J., Jacob, D. J., Wofsy, S. C., Kort, E. A., Worden, J. R., Kulawik, S. S., Henze, D. K., Kopacz, M., and Payne, V. H.: Validation of TES methane with HIPPO aircraft observations: implications for inverse modeling of methane sources, Atmos. Chem. Phys., 12, 1823-1832, doi:10.5194/acp-12-1823-2012, 2012.

Wecht, K. J., Jacob, D. J., Frankenberg, C., Jiang, Z., and Blake, D. R.: Mapping of North American methane emissions with high spatial resolution by inversion of SCIAMACHY satellite data, J. Geophys. Res.-Atmos., 119, 7741-7756, 2014a.

Wecht, K. J., Jacob, D. J., Sulprizio, M. P., Santoni, G. W., Wofsy, S. C., Parker, R., Bösch, H., and Worden, J.: Spatially resolving methane emissions in California: constraints from the CalNex aircraft campaign and from present (GOSAT, TES) and future (TROPOMI, geostationary) satellite observations, Atmos. Chem. Phys., 14, 8173-8184, doi:10.5194/acp-14-8173-2014, 2014b.

West, J. J. and Fiore, A. M.: Management of tropospheric ozone by reducing methane emissions, Environ. Sci. Technol., 39, 46854691, 2005

West, J. J., Fiore, A. M., Horowitz, L. W., and Mauzerall, D. L.: Global health benefits of mitigating ozone pollution with methane emission controls, P. Natl. Acad. Sci. USA, 103, 39883993, 2006.
West, J. J., Fiore, A. M., and Horowitz, L. W.: Scenarios of methane emission reductions to 2030: abatement costs and co-benefits to ozone air quality and human mortality, Climatic Change, 114, 441-461, 2012.

Worden, J., Kulawik, S., Shephard, M. W., Clough, S. A., Worden, H., Bowman, K., and Goldman, A.: Predicted errors of tropospheric emission spectrometer nadir retrievals from spectral window selection, J. Geophys. Res., 109, D09308, doi:10.1029/2004JD004522, 2004.

Worden, J., Kulawik, S., Frankenberg, C., Payne, V., Bowman, K., Cady-Peirara, K., Wecht, K., Lee, J.-E., and Noone, D.: Profiles of $\mathrm{CH}_{4}, \mathrm{HDO}, \mathrm{H}_{2} \mathrm{O}$, and $\mathrm{N}_{2} \mathrm{O}$ with improved lower tropospheric vertical resolution from Aura TES radiances, Atmos. Meas. Tech., 5, 397-411, doi:10.5194/amt-5-397-2012, 2012.

Worden, J. R., Turner, A. J., Bloom, A., Kulawik, S. S., Liu, J., Lee, M., Weidner, R., Bowman, K., Frankenberg, C., Parker, R., Payne, V. H.: Quantifying lower tropospheric methane concentrations using GOSAT near-IR and TES thermal IR measurements, Atmos. Meas. Tech., 8, 3433-3445, doi:10.5194/amt-8 3433-2015, 2015.

Xiao, Y., Logan, J. A., Jacob, D. J., Hudman, R. C., Yantosca, R., and Blake, D. R.: Global budget of ethane and regional constraints on US sources, J. Geophys. Res.-Atmos., 113, D21306, doi:10.1029/2007JD009415, 2008.

Yevich, R. and Logan, J. A.: An assessment of biofuel use and burning of agricultural waste in the developing world, Global Biogeochem. Cy., 17, 1095, doi:10.1029/2002GB001952, 2003.

Zhu, L., Henze, D., Bash, J. O., Cady-Pereira, K. E., Shephard, M. W., Luo, M., and Capps, S. L.: Sources and impacts of atmospheric $\mathrm{NH}_{3}$ : Current understanding and frontiers for modeling, measurements, and remote sensing in North America, Current Pollution Reports, 1, 95-116, 2015. 